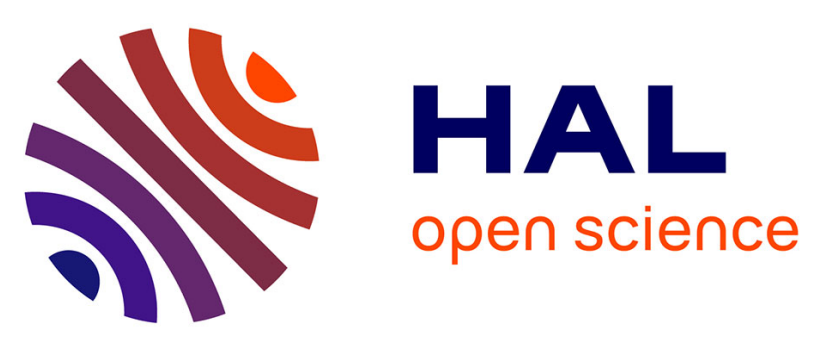

\title{
Tropical storm-induced near-inertial internal waves during the Cirene experiment: Energy fluxes and impact on vertical mixing
}

Yannis Cuypers, Xavier Le Vaillant, Pascale Bouruet-Aubertot, Jérôme Vialard, Michael J. Mcphaden

\section{To cite this version:}

Yannis Cuypers, Xavier Le Vaillant, Pascale Bouruet-Aubertot, Jérôme Vialard, Michael J. Mcphaden. Tropical storm-induced near-inertial internal waves during the Cirene experiment: Energy fluxes and impact on vertical mixing. Journal of Geophysical Research. Oceans, 2013, 118 (1), pp.358-380. 10.1029/2012JC007881 . hal-01208047

\section{HAL Id: hal-01208047 https://hal.science/hal-01208047}

Submitted on 2 Jan 2022

HAL is a multi-disciplinary open access archive for the deposit and dissemination of scientific research documents, whether they are published or not. The documents may come from teaching and research institutions in France or abroad, or from public or private research centers.
L'archive ouverte pluridisciplinaire HAL, est destinée au dépôt et à la diffusion de documents scientifiques de niveau recherche, publiés ou non, émanant des établissements d'enseignement et de recherche français ou étrangers, des laboratoires publics ou privés. 


\title{
Tropical storm-induced near-inertial internal waves during the Cirene experiment: Energy fluxes and impact on vertical mixing
}

\author{
Y. Cuypers, ${ }^{1}$ X. Le Vaillant, ${ }^{1}$ P. Bouruet-Aubertot, ${ }^{1}$ J. Vialard, ${ }^{1}$ and M. J. McPhaden ${ }^{2}$ \\ Received 9 January 2012; revised 22 November 2012; accepted 7 December 2012; published 30 January 2013.
}

[1] Near-inertial internal waves (NIW) excited by storms and cyclones play an essential role in driving turbulent mixing in the thermocline and interior ocean. Storm-induced mixing may be climatically relevant in regions like the thermocline ridge in the southwestern Indian Ocean, where a shallow thermocline and strong high frequency wind activity enhance the impact of internal gravity wave-induced mixing on sea surface temperature. The Cirene research cruise in early 2007 collected ship-borne and mooring vertical profiles in this region under the effect of a developing tropical cyclone. In this paper, we characterize the NIW field and the impact of these waves on turbulent mixing in the upper ocean. NIW packets were identified down to $1000 \mathrm{~m}$, the maximum depth of the measurements. We estimated an NIW vertical energy flux of up to $2.5 \mathrm{~mW} \mathrm{~m}^{-2}$ within the pycnocline, which represents about $10 \%$ of the maximum local wind power input. A non-negligible fraction of the wind power input is hence potentially available for subsurface mixing. The impact of mixing by internal waves on the upper ocean heat budget was estimated from a fine-scale mixing parameterization. During the first leg of the cruise (characterized by little NIW activity), the average heating rate due to mixing was $\sim 0.06^{\circ} \mathrm{C} \mathrm{month}^{-1}$ in the thermocline $\left(23-24 \mathrm{~kg} \mathrm{~m}^{-3}\right.$ isopycnals). During the second leg, characterized by strong NIW energy in the thermocline and below, this heating rate increased to $0.42{ }^{\circ} \mathrm{C}$ month ${ }^{-1}$, indicative of increased shear instability along near inertial wave energy pathways.

Citation: Cuypers, Y., X. Le Vaillant, P. Bouruet-Aubertot, J. Vialard, and M. J. McPhaden (2013), Tropical storminduced near-inertial internal waves during the Cirene experiment: Energy fluxes and impact on vertical mixing, J. Geophys. Res. Oceans, 118, 358-380, doi:10.1029/2012JC007881.

\section{Introduction}

[2] Internal wave breaking is one of the main processes inducing turbulent mixing in the stratified ocean. The importance of this process for determining large-scale patterns of ocean circulation (like the meridional overturning circulation) has been highlighted in numerous studies [e.g., Marotzke and Scott, 1999; Wunsch and Ferrari, 2004]. There is also evidence that near-surface mixing can have a considerable climatic influence in regions where the sea surface temperature is high and sustains deep atmospheric convection [e.g., KochLarrouy et al., 2008]. This underlines the requirement for a more comprehensive understanding of energy pathways from

\footnotetext{
${ }^{1}$ Laboratoire d'Océanographie Expérimentation et Approches Numériques, CNRS, UPMC, IRD, Paris, France. USA.

${ }^{2}$ Pacific Marine Environmental Laboratory, NOAA, Seattle, Washington,

Corresponding author: Y. Cuypers, LOCEAN - Case 100, Université Pierre et Marie Curie, 75232 Paris CEDEX 05, France. (Yannis.Cuypers@ locean-ipsl.upmc.fr)

C2012. American Geophysical Union. All Rights Reserved. 2169-9275/13/2012JC007881
}

large scales to mixing scales and especially of the lifecycle of internal waves from generation to breaking.

[3] The two main sources of internal gravity waves are tides and high frequency atmospheric forcing [Munk and Wunsch, 1998; Wunsch, 1998]. The strong wind and wind vector rotation associated with tropical cyclones induce an energetic inertial current response. To the right of the cyclone track (in the Northern Hemisphere), this results in intense kinetic energy generation in the upper ocean, because wind stress vectors rotate in the same direction as storm-generated oceanic currents, maximizing power input to the surface ocean [e.g., Price, 1981] and wind stress is larger on the right side of the storm track, partly due to the storm translation speed [Chang and Anthes, 1978]. In the Southern Hemisphere, strong inertial currents and enhanced mixing occur on the left side of the storm track. A large fraction of this kinetic energy is consumed by vertically mixing warm surface water down into the thermocline [Jaimes and Shay, 2009]. But a fraction of this energy input radiates down in the interior ocean under the form of near-inertial internal waves (hereafter NIW). There is a need to evaluate the fraction of the cyclone-generated kinetic energy that penetrates in the interior ocean. This is important for understanding the cyclone response (the cyclone-induced surface cooling will be more intense if most of the energy is consumed 
locally) and for the general circulation (the radiated internal gravity wave will break elsewhere, contributing to turbulent mixing in the interior ocean).

[4] Many studies have used the power input from the wind to surface currents to obtain an upper bound of the power available for NIW [e.g., Alford, 2001, 2003; Watanabe and Hibiya, 2002; Von Storch et al., 2007; Furuichi et al., 2008]. Detailed analyses of NIW observations provide estimates of energy fluxes [Hebert and Moum, 1994; Qi et al., 1995; Alford and Gregg, 2001; Bouruet-Aubertot et al., 2005; Jaimes and Shay, 2010], but these energy fluxes are seldom compared to the wind power input at near-inertial frequencies. A few studies however provide an estimate of the fraction of energy that propagates at depth. Von Storch et al. [2007] found that about 30\% of the wind-generated power penetrates below $110 \mathrm{~m}$ depth using a $1 / 10^{\circ}$ ocean general circulation model. Furuichi et al. [2008] show that a large fraction of the NIW energy is concentrated in high vertical modes with maximum amplitude in the upper $150 \mathrm{~m}$, while only $13-25 \%$ of the wind power input penetrates below $150 \mathrm{~m}$. A similar fraction was found by Zhai et al. [2009] in $1 / 12^{\circ}$ model simulations.

[5] The southwestern tropical Indian Ocean is a region of particular interest for studies of NIW-induced mixing. First, it is an area that encompasses an ascending branch of the thermohaline circulation, which is largely driven by mixing [Broecker, 1991]. Second, the $5^{\circ} \mathrm{S}-10^{\circ} \mathrm{S}$ band of the Indian ocean is a region where a shallow thermocline, driven by climatological Ekman pumping [McCreary et al., 1993], coexists with high sea surface temperatures (hereafter SSTs), close to the threshold for development of deep atmospheric convection in winter. The SST responds readily to atmospheric forcing because of the shallow thermocline, while moderate SST anomalies can feedback on the atmospheric circulation by modulating the deep atmospheric convection. Such a situation is conducive to strong ocean-atmosphere coupling as pointed out by Xie et al. [2002] and Schott et al. [2009].

[6] The ocean and atmosphere covary on a variety of time scales in this region [Vialard et al., 2009]. At time scales of a few days, this is a region of cyclogenesis. The Madden-Julian oscillation is an intraseasonal, large-scale perturbation of the deep atmospheric convection that generally develops in the Indian Ocean, before propagating eastward into the Pacific Ocean [Zhang, 2005]. The Madden-Julian oscillation has a clear intraseasonal surface signature in the southwestern Indian Ocean [e.g., Vialard et al., 2008]. At interannual time scale, the Indian Ocean Dipole is a large-scale climate anomaly analogous to the El Niño phenomenon in the Pacific [e.g., Saji et al., 1999; Webster et al., 1999] with a prominent subsurface signature in the $5^{\circ} \mathrm{S}-10^{\circ} \mathrm{S}$ band [Vialard et al., 2009].

[7] Vertical mixing plays a significant role in the upper ocean variability on all these time scales. The surface temperature response to cyclones is for example known to be largely the result of enhanced mixing associated with the near-inertial response to cyclone winds [Price, 1981]. Several studies also suggest that mixing and upwelling contribute more modestly, but in a non-negligible way, to the SST signature of the Madden-Julian oscillation [Lloyd and Vecchi, 2010; Jayakumar et al., 2011]. Finally, there is a clear contribution of vertical mixing to the seasonal evolution of the upper ocean in this region [Foltz et al., 2010].
[8] There is thus a need to better diagnose vertical mixing induced by the near-inertial ocean response in this region. The Cirene research cruise [Vialard et al., 2009] enabled collection of in situ atmospheric and oceanic observations in this region (see Figure 1a for the location of the cruise) during more than one month in January-February 2007. This region is characterized by strong wind variations in the near-inertial frequency range associated with tropical storms, synoptic variations, and mesoscale atmospheric convection (see Figure 1b). In particular, a tropical storm developed in the vicinity of the Cirene station at $8^{\circ} \mathrm{S}, 67^{\circ} \mathrm{E}$ on 27 January and later became tropical cyclone Dora on 2 February at about $17^{\circ} \mathrm{S}$ (see Figure 2).

[9] In this paper, we use observations from the Cirene experiment to characterize NIW variability excited by this storm and the impact of wave breaking on vertical turbulent diffusion. One of our objectives is to estimate the ratio of the

\section{a) 2-7 day Qscat wind speed band std in DJFM}

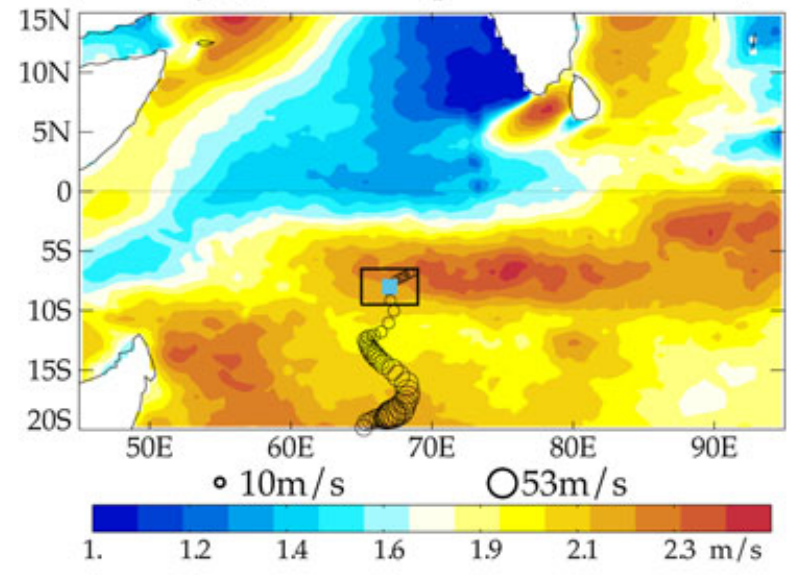

b) Bathymetry

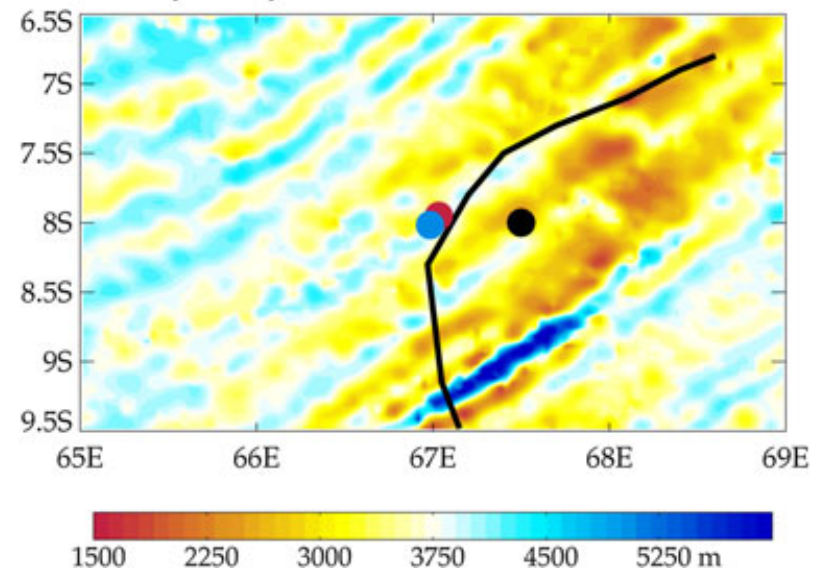

Figure 1. The location of the cruise long station is indicated by a blue square on Figure 1a, while the box indicates the zoom of the cruise region shown on Figure 1b. The open circles indicate the Dora cyclone location and their size the maximum wind intensity from the IBTraCs database. On Figure 1b, the storm is indicated by a thick line and the bathymetry [Smith and Sandwell, 1997] is shown in colors. The black circle on Figure $1 \mathrm{~b}$ indicates the Suroit (and CTD profiles) mean location. The blue circle indicates the ATLAS mooring location. The red circle indicates the ATLAS ADCP location. 
CUYPERS ET AL.: STORM-INDUCED NIW DURING CIRENE

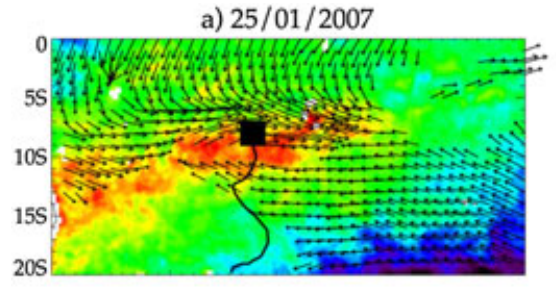

b) $27 / 01 / 2007$

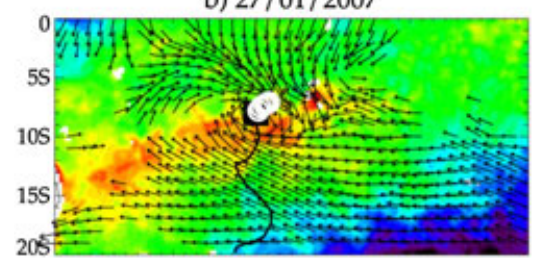

c) $29 / 01 / 2007$

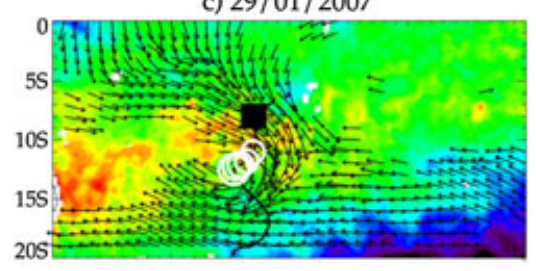

d) $03 / 02 / 2007$

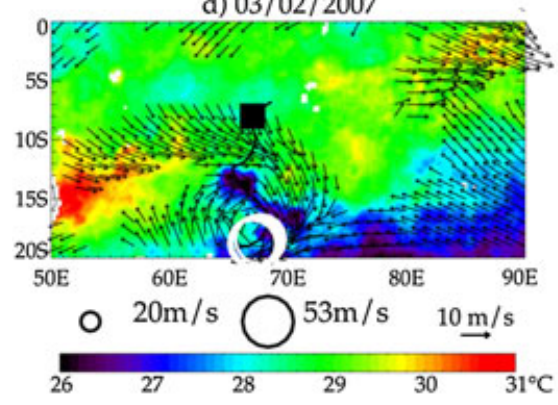

e) Dora maximum winds
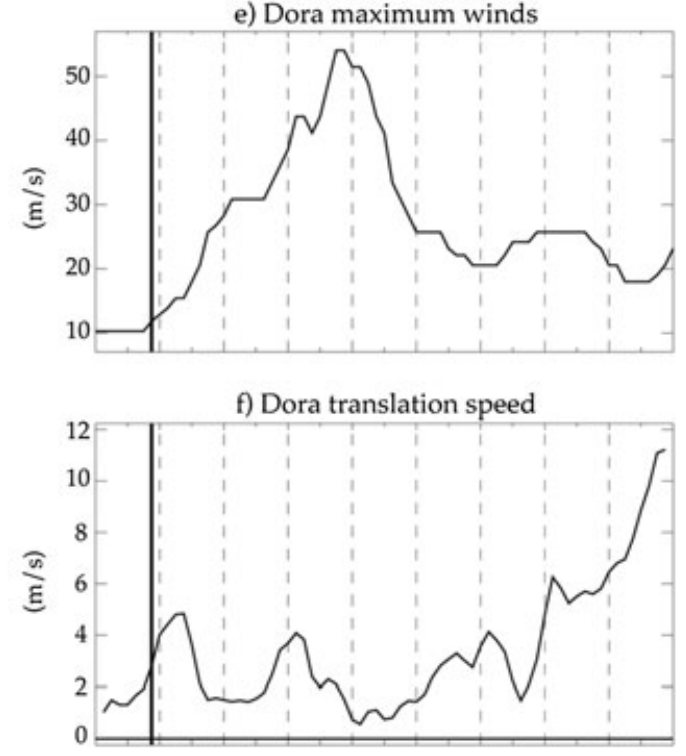

g) Dora radius of maximum winds

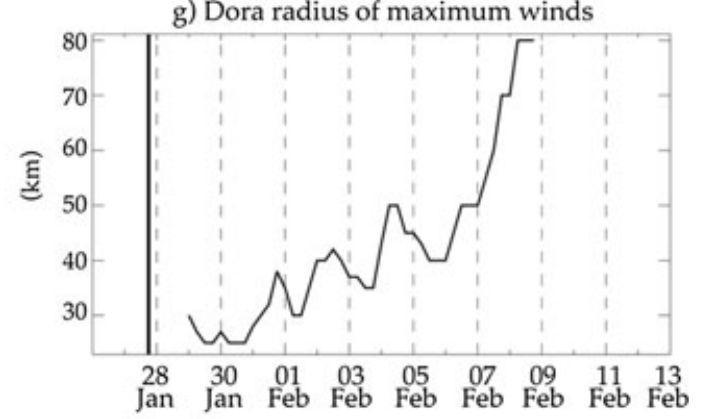

Figure 2. (a-d) Qscat wind map (arrows) and TMI SST maps (color scale). The open circles show Dora trajectory (the maximum wind intensity is indicated by the size of the open circle, with a scale below Figure 2d), the black square shows the ATLAS mooring and FP station location. (e-g) Characteristics of the Dora cyclone obtained from Météo France regional center in La Réunion. (e) Dora maximum winds (m/s). (f) Dora translation speed $(\mathrm{m} / \mathrm{s})$. $(\mathrm{g})$ Dora radius of maximum winds $(\mathrm{km})$. The black vertical line indicates the date at which Dora center is closest to the TC mooring. At this date, Dora was still at the "tropical storm" stage and the eye was not fully formed, which explains why estimates of the radius of maximum wind are only available later.

wind power input that penetrated below the thermocline and became available for interior ocean mixing. The paper is organized as follows. In section 2 , we describe the Cirene measurements and give an overview of the meteorological conditions and upper ocean response to the passage of Dora. Section 3 is devoted to the analysis of NIW. Different wave groups are identified down to $1000 \mathrm{~m}$ and their energy fluxes are estimated. Estimates of kinetic energy dissipation rates and vertical eddy diffusivity are presented in section 4 . Section 5 provides discussion and conclusions.

\section{Meteorological Conditions and Upper Ocean Response}

\subsection{Observations}

[10] The Cirene cruise and observations are described in detail in Vialard et al. [2009] and the associated supplementary information. The Cirene cruise comprised two legs, with each leg involving a station near $8^{\circ} \mathrm{S}, 67^{\circ} 30^{\prime} \mathrm{E}$ of $10-12$ days duration (14-26 January and 4-15 February). The interval between the two legs was necessary for refueling and supply purposes, and by chance coincided with the formation of tropical storm Dora. A highly instrumented ATLAS (Autonomous Temperature Line Acquisition System) mooring was deployed at $8^{\circ} \mathrm{S}, 67^{\circ} \mathrm{E}$ (position referred hereafter as "ATLAS Mooring") at the beginning of the first leg, within the framework of the Research Moored Array for the African-Asian-Australian Monsoon Analysis and Prediction program (RAMA) [McPhaden et al., 2009]. This mooring was recovered and then redeployed with lighter instrumentation at the end of the second leg. We summarize the ship-borne and mooring observations that we use below.

[11] 1. Lowered acoustic Doppler current profiler (LADCP) and conductivity temperature depth (CTD) casts were performed from the R/V Suroît near $8^{\circ} \mathrm{S}, 67^{\circ} 30^{\prime} \mathrm{E}$ 
(position referred hereafter as "FP station" for Fixed Point station) during the two legs of the Cirene cruise. CTD measurements were performed roughly every $20 \mathrm{~min}$ down to $500 \mathrm{~m}$, while CTD-LADCP profiles were conducted down to $1000 \mathrm{~m}$ roughly every $6 \mathrm{~h}$. Post-processed CTD data have $1 \mathrm{~m}$ vertical resolution, while post-processed LADCP data provide horizontal currents with $8 \mathrm{~m}$ vertical resolution.

[12] 2. The mooring measurements cover the 13 January to 15 February period. The ATLAS buoy deployed at $7^{\circ} 57^{\prime} \mathrm{S}, 67^{\circ} 02^{\prime} \mathrm{E}$ (hereafter referred to by its nominal position of $8^{\circ} \mathrm{S}, 67^{\circ} \mathrm{E}$, Figure 1) measured subsurface temperature and salinity, as well as air temperature, relative humidity, wind velocity, downward shortwave and longwave radiation, barometric pressure, and precipitation. Ocean temperatures were measured at 1, 5, 10, 20, $40,60,80,100,120,140,180,300$, and $500 \mathrm{~m}$ (every $10 \mathrm{~min}$ ) and salinity at $1,5,10,20,30,40,50,60,80$, 100 , and $140 \mathrm{~m}$ (every $10 \mathrm{~min}$, then smoothed to $1 \mathrm{~h}$ averages to reduce noise). Meteorological measurements were measured 3-4 $\mathrm{m}$ above sea level and stored every $10 \mathrm{~min}$, with the exception of barometric pressure which was measured once per hour. A $300 \mathrm{kHz}$ acoustic Doppler current profile (ADCP) was deployed on a subsurface mooring $9200 \mathrm{~m}$ away from the ATLAS mooring, at $8^{\circ} 01^{\prime} \mathrm{S}, 66^{\circ} 59^{\prime} \mathrm{E}$. This subsurface ADCP provided horizontal current velocities at hourly resolution and at $4 \mathrm{~m}$ vertical resolution between 20 and $180 \mathrm{~m}$ depth.

[13] Net heat fluxes and wind stresses were estimated from 10 min ATLAS data using the COARE v3 algorithm [Fairall et al., 2003]. The mixed layer depth $h$ at the ATLAS mooring site was estimated as the depth for which $\rho(h)=\rho(5 \mathrm{~m})+0.015$ $\mathrm{kg} \mathrm{m}^{-3}$, by assuming a linear stratification between two measurements. This choice allows for direct estimation of the nighttime mixed layer and filters out the diurnal cycle during period of low winds. Because the ATLAS mooring density measurements have a limited vertical resolution (generally $10 \mathrm{~m}$ ), we have compared daily averages of the mixed layer depth estimates at the ATLAS mooring with simultaneously available daily averages from the FP station CTD (which has a $1 \mathrm{~m}$ vertical resolution after processing): there is a 0.98 correlation, a $60 \mathrm{~cm}$ bias, and a $1.2 \mathrm{~m}$ RMS error on daily average mixed layer depth estimates from the two data sources. This indicates that the ATLAS mooring mixed layer depth estimates can be used confidently.

[14] We use other data sets to provide a large-scale picture of the signals associated with cyclone Dora. For SST, we use optimally interpolated data from the Tropical Rainfall Measurement Mission Microwave Instrument (TMI) and Advanced Microwave Scanning Radiometer for EOS (AMSR-E) produced by remote sensing systems. AMSR-E is particularly interesting owing to its ability to see through clouds and so to monitor surface cooling associated with a cyclone. The AMSR-E product is available with a daily resolution on a $0.25^{\circ}$ grid. For winds, we use gridded estimates of $10 \mathrm{~m}$ winds from the QuikSCAT scatterometer produced at Centre ERS d'Archivage et de Traitement (CERSAT) [Bentamy et al., 2002]. This product is available with daily resolution on a $0.5^{\circ}$ grid. It should be noted that this gridded product does not resolve the very strong winds associated with the eyewall of a fully developed cyclone, but it gives a reasonable estimate of the large-scale structure in the early stage of the storm development as we observed during Cirene. We use the Dora trajectory, maximum wind intensity and radius of maximum winds provided by the International Best Track Archive for Climate Stewardship (IBTrACS) project [Knapp et al., 2010] and by the Météo France Regional Specialized Meteorological Center in La Réunion Island. The Ocean Surface Current Analysis in Realtime (OSCAR) product [Bonjean and Lagerloef, 2002] is also used to provide an estimate of surface vorticity at the measurement site. Comparisons between OSCAR and 5 day averaged ADCP near-surface currents at the ATLAS site indicate a 0.81 correlation for both zonal and meridional components over the January 2007 to December 2009 period, indicating that OSCAR current estimates are reasonable for this location.

\subsection{Climatic and Meteorological Conditions}

\subsubsection{Large-Scale Conditions}

[15] Interannual anomalies were characterized by an anomalously warm and fresh upper ocean and deep thermocline $(\sim 80 \mathrm{~m}$ instead of $40 \mathrm{~m}$ value in the World Ocean ATLAS 2009 climatology [Locarnini et al., 2010]) at $8^{\circ} \mathrm{S}, 67^{\circ} \mathrm{E}$ during the cruise. There was an Indian Ocean Dipole in 2006 [Vinayachandran et al., 2007] that highly influenced the oceanic state at the Cirene location in early 2007 [Vialard et al., 2009]. At intraseasonal time scales, the meteorological conditions were dominated by a break phase of the Madden-Julian oscillation during most of the cruise, i.e., low winds and high solar heat fluxes [Vialard et al., 2009].

[16] These low wind conditions were disturbed by the formation of a tropical depression that later became and named storm Dora. Figure 2 provides a synoptic view of the satellite-derived wind and SST in the cruise region and the main characteristics of Dora (maximum winds, radius of maximum winds, and translation speed). A westerly wind burst developed on 25 January, breaking the low wind conditions that prevailed until then. This was the prelude to the tropical depression that formed around 26 January, with a clear development of cyclonic winds around the cruise site. The depression came closest to the mooring site at the end of 27 January (Figure 2b), with still relatively low maximum winds (around $10-12 \mathrm{~m} \mathrm{~s}^{-1}$, Figure 2e). The depression reached the tropical storm stage (maximum winds of $\sim 17 \mathrm{~m} \mathrm{~s}^{-1}$ ) and a clear eye of $\sim 30 \mathrm{~km}$ formed early on 29 January, while the storm was already $300-400 \mathrm{~km}$ south of the mooring (Figures $2 \mathrm{c}$ and $2 \mathrm{~g}$ ). Dora reached the cyclone stage (maximum winds of $\sim 33 \mathrm{~m} \mathrm{~s}^{-1}$ ) on 1 February at about $17^{\circ} \mathrm{S}$ with maximum winds on 3 February near $20^{\circ} \mathrm{S}$ (Figures 2c-2e). The mooring site stayed under the influence of relatively strong winds associated with the storm large-scale structure from 25 January to 3 February, as clearly shown in Figure 2. During the entire period, Dora moved relatively slowly, with translation speed in the $2-4 \mathrm{~m}$ $\mathrm{s}^{-1}$ range although it later accelerated significantly much further south, on 9 February (Figure $2 \mathrm{~g}$ ).

[17] The very high SST values which were present before the cyclone (see Figure 2a) progressively disappeared under the influence of strong winds (Figures $2 \mathrm{~b}$ and $2 \mathrm{c}$ ). A strong cooling on the left of the cyclone track can be seen on Figure $2 \mathrm{~d}$. This is characteristic of increased mixing driven by tropical storms [Price, 1981; Shay et al., 1989]. 


\subsubsection{Local Conditions at $8^{\circ} \mathrm{S}, 67^{\circ} \mathrm{E}$}

[18] Meteorological measurements from the ATLAS buoy are displayed in Figure 3. Time series of atmospheric forcing are very similar at the $\mathrm{R} / \mathrm{V}$ Suroit site, which is expected considering the relatively small $55 \mathrm{~km}$ distance between the two sites. The Cirene cruise in general was characterized by a "break" phase of the Madden-Julian oscillation, i.e., the absence of large-scale convection, and hence no clouds, and weak winds. Three distinct periods however characterize the atmospheric forcing. During the first period (13-23 January, hereafter, the "pre-cyclone period" that we will also use for leg 1 , since they almost coincide), calm conditions characteristic of the break phase of the Madden-Julian oscillation prevailed with wind velocity $<5 \mathrm{~m} \mathrm{~s}^{-1}$, daily averaged air temperature between $28^{\circ} \mathrm{C}$ and $29^{\circ} \mathrm{C}$, strong daytime solar radiation, and almost no rainfall.

[19] The second period (24 January to 2 February, hereafter the "cyclone period") is dominated by the influence of Dora (as very clearly indicated by the wind patterns on Figures $2 \mathrm{c}$ and 2d). The signature of Dora is clear in all meteorological variables. The pressure record (Figure $3 b$ ) at the mooring site clearly shows the passage of the depression over the site on 27 January, coinciding with weak winds within the eye of the depression (Figures $2 \mathrm{~b}$ and $3 \mathrm{a}$ ). The wind intensity increased rapidly up to $10 \mathrm{~m} \mathrm{~s}^{-1}$ on 25 January and again on 28 January after the passage of the eye. Daily mean air temperature dropped by about $2^{\circ} \mathrm{C}$ and the daily mean heat fluxes decreased to negative values associated with strong winds in the eyewall.

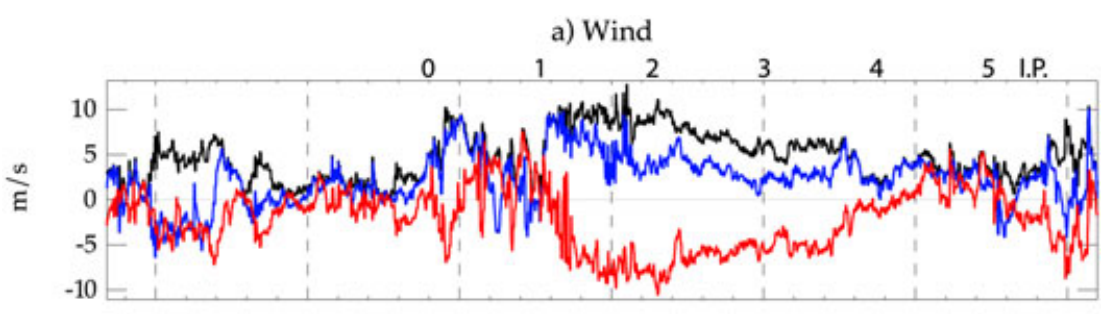

b) Pressure
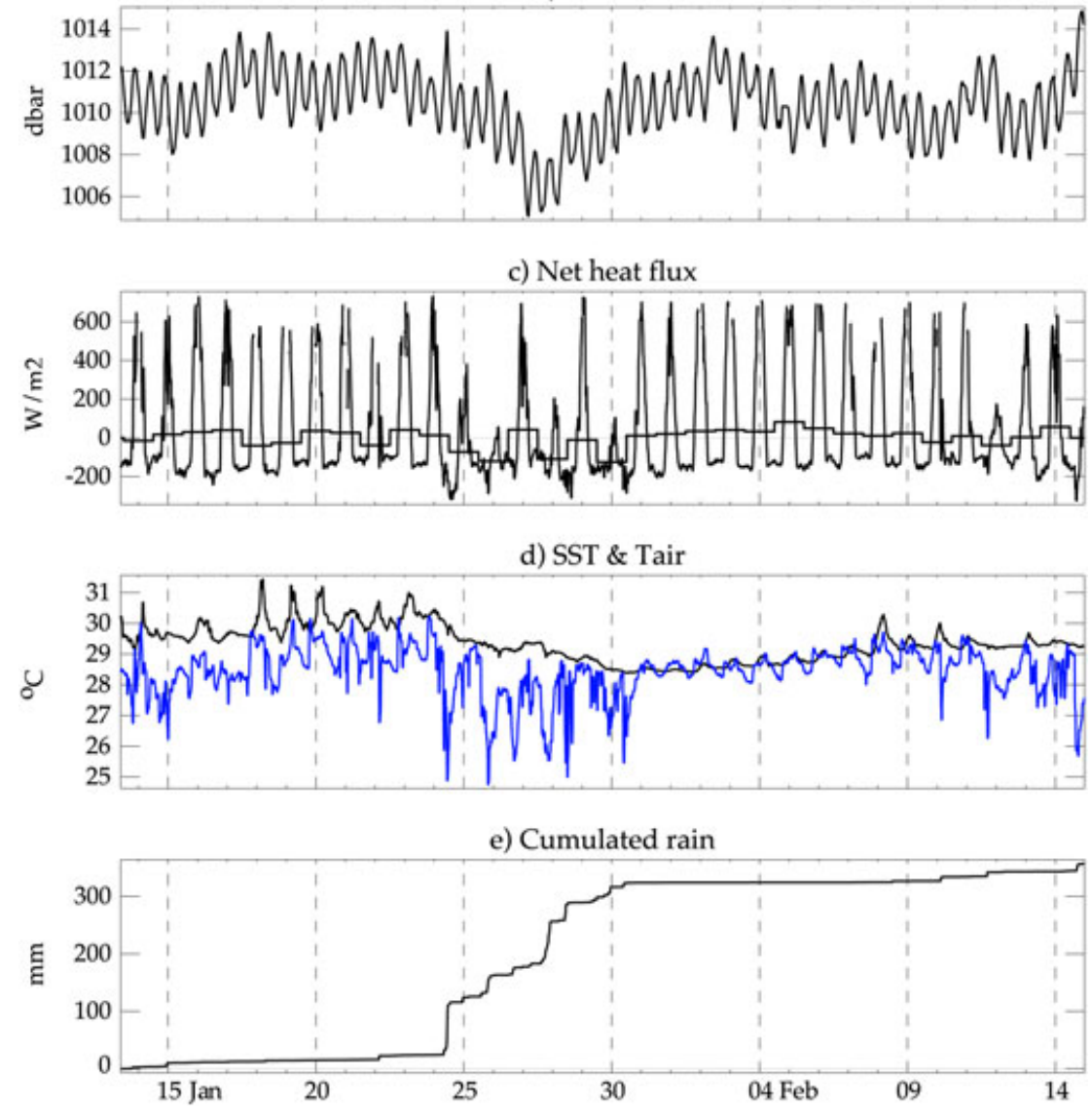

Figure 3. Meteorological data from the ATLAS mooring. (a) Wind stress, red $\boldsymbol{\tau}^{\mathbf{x}}$, blue $\boldsymbol{\tau}^{\mathbf{y}}$ black total, (b) pressure, (c) net heat flux (with the thicker line indicating the daily mean), (d) air temperature (blue) and sea surface temperature (black), and (e) accumulated precipitation. These plots were computed from the 10 min average ATLAS mooring data, with a 50 min median filter. The net heat flux was computed by applying the COARE v3 bulk algorithm. The time axis below each plot indicates the dates, while the time axis above the upper plot indicates the number of inertial periods after the first wind burst (e.g., after 24 January 2007). 
Most of the rainfall during the observation period was associated with the storm passage with about $300 \mathrm{~mm}$ in 5 days. Around 2 February, the cyclone moved away (Figure 2), but intensified (Figure 2e) and was still associated with winds above $7 \mathrm{~m} \mathrm{~s}^{-1}$ at the mooring site (Figure 3a). The relatively long-lasting period of strong winds (24 January to 2 February) is due to the consecutive influence of the close but still weak tropical depression, followed by the remote influence of the intensifying storm and cyclone as it travels south.

[20] The third period (hereafter "post cyclone period", which we will also use for leg 2 since the two periods almost coincide) extended from 1 to 11 February and showed the progressive return to calm conditions characteristic of a Madden-Julian oscillation break phase as Dora moved away. Rainfall almost ceased and net heat flux and pressure came back to values comparable to the first period. It was only at the end of the observation that disturbed conditions developed again in association with a tropical depression (future cyclone Favio) and the onset of an active MaddenJulian oscillation phase [Vialard et al., 2009].

\subsection{Upper Ocean Response}

\subsubsection{Thermal and Haline Response}

[21] Figure 4 shows clearly the strong surface layer signature of Dora's passage. During the pre-cyclone period, calm conditions favored a warm surface layer with temperature over $29^{\circ} \mathrm{C}$ and a strong diurnal cycle with $1-2^{\circ} \mathrm{C} \mathrm{SST}$ fluctuations at $1 \mathrm{~m}$ depth [Vialard et al., 2009]. A strong pycnocline was found around $80 \mathrm{~m}$ depth resulting in a maximum of $0.025 \mathrm{rads}^{-1}$ for the Brunt Vaisala profile averaged over leg 1 (Figure 4f).

[22] Salinity in the surface layer varied only moderately under the influence of moderate wind events $\left(5 \mathrm{~m} \mathrm{~s}^{-1}\right)$ and precipitation (Figure 3). A striking feature of the salinity plot is an intrusion layer observed at $100 \mathrm{~m}$ depth starting on 19 January (Figure 4d). However, this salinity intrusion had only a weak influence on the density, which was mainly driven by temperature.

[23] During the pre-cyclone period, the mixed layer was quite shallow (Figure 4), only reaching a maximum of $20 \mathrm{~m}$ depth in response to moderate wind events. During the cyclone period, Dora had a clear influence on surface layer characteristics. Strong wind stress $\left(0.2 \mathrm{~N} \mathrm{~m}^{-2}\right.$; Figure $4 a$ ) resulted in a deepening of the mixed layer up to $35 \mathrm{~m}$ depth from about 23 to 29 January. The mixed layer deepening occurred roughly 3-4 days after the first wind burst (i.e., after about one inertial period, which is 3.6 days at $8^{\circ} \mathrm{S}$ ) and is probably indicative of the effect of turbulent wind erosion followed by near-inertial shear instability. As a result of stronger winds, the diurnal cycle of temperature at 1 and $5 \mathrm{~m}$ was suppressed. Intense mixing near the surface resulted in a clear decrease of the stratification in the top $40 \mathrm{~m}$ during the cyclone period (Figure 4f). Salinity decreased over a gradually thickening layer from 26 January to 2 February, in association with the strong rainfall associated with Dora. The pycnocline depth decreased from 80 to $70 \mathrm{~m}$ around 27 January. This shoaling of the pycnocline depth is probably the result of a transient upwelling response within a distance of about twice the radius of maximum winds [O'Brien and Reid, 1967]. Scatterometer wind stresses (not shown) [Bentamy et al., 2002] seem to support that hypothesis. Note that when removing low-frequency trends from the mixed layer variations, a clear mixed layer depth oscillation at near-inertial period appears around 28 January (one inertial period after the beginning of the cyclone phase) and is observed until 11 February (five inertial periods after the beginning of the cyclone phase), while oscillations observed before 28 January are sub-inertial (Figure 4e). This observation is probably indicative of inertial pumping [Gill, 1984] superimposed on the near-inertial shear instabilitydriven mixed layer deepening. After 2 February (during the post-cyclone period), the wind stress started to decrease as cyclone Dora moved away. This decrease was associated with a restratification of the upper layer, a shallower mixed layer, and pycnocline that progressively deepened to $80 \mathrm{~m}$ depth. However the top $40 \mathrm{~m}$ remained well mixed compared to the pre-cyclone period (Figure 4f).

\subsubsection{Current Response}

[24] Since $8^{\circ} \mathrm{S}$ is a transition region between the eastward South Equatorial Countercurrent and westward South Equatorial Current, mean currents are normally expected to be quite weak. However, during Cirene, a mean westward component $\left(32 \mathrm{~cm} \mathrm{~s}^{-1}\right)$ with a weak southward component was observed due to strong geostrophic current anomalies associated with the aftermath of the 2006 Indian Ocean Dipole event [Vialard et al., 2009].

[25] Our interest here is more in high frequency fluctuations of the current, which are obvious from the meridional velocity time-depth section displayed in Figure 5. The most striking feature is the presence of inertial waves in the mixed layer and NIW below, characterized by strong velocity fluctuations $\left( \pm 40 \mathrm{~cm} \mathrm{~s}^{-1}\right.$ in the pycnocline and in the surface layer). Similar fluctuations are observed on the zonal velocity component (not shown).

[26] This near-surface inertial response appears around 25 January in response to the strong wind stresses associated with the passage of Dora. The near-surface inertial response only lasts for a few days after the intense wind stresses and has largely disappeared by 6 February.

[27] This near-surface response, however, drives vertical motions of the pycnocline by inertial pumping (Figure 4e) [Gill, 1984], hence progressively transferring energy to the interior ocean by exciting NIW. There are signs of upward phase propagation of the velocity fluctuations associated with NIW below $40 \mathrm{~m}$ depth in both ADCP and LADCP signals, indicative of downward energy propagation. The upward phase propagation is less obvious on the LADCP record due to the lower $\sim 6 \mathrm{~h}$ time resolution, maybe because of aliasing by the tidal signal which is also strong (the sampling interval is $1 / 14$ inertial period, which should resolve the NIW signal). We will show this more convincingly in Figure 7. NIW current fluctuations are clearly seen down to $\sim 200 \mathrm{~m}$ in the ADCP record (with $\sim 0.15 \mathrm{~m} \mathrm{~s}^{-1}$ fluctuations at this depth). Similar current fluctuations can be seen down to $1000 \mathrm{~m}$ in the LADCP record (Figure 5b).

[28] We will show in section 3 that the NIW packets have typical horizontal wavelength of at least $300 \mathrm{~km}$. Therefore considering the $50 \mathrm{~km}$ separation between the ATLAS (and ADCP) moorings and the FP station, we can assume that measurements at those locations sample the same wave. 


\section{Near-Inertial Internal Waves: Characteristics and Energy Fluxes}

\subsection{Spectral Analysis}

[29] In order to characterize the frequency content of the internal wave field, power spectra density (PSD) of horizontal currents were computed every $4 \mathrm{~m}$ at depths ranging from 22 to $162 \mathrm{~m}$ at the ATLAS mooring and every $8 \mathrm{~m}$ from 0 to $1000 \mathrm{~m}$ at the FP station. Weighted ensemble averages of the spectra within $20 \mathrm{~m}$ vertical bins were then performed to reduce uncertainties. The spectra were computed over the whole record length, i.e., 32.75 days at the ATLAS mooring, 11.5 days (pre-cyclone period), and 11.28 days (post-cyclone period) at the FP station (Figure 6).

[30] The overall shape of the power spectrum agrees well with semi-empirical Garret and Munk (GM hereafter) spectrum as modified by Cairns and Williams [1976] for frequencies higher than the inertial frequency $f$ and shows an energy level comparable to the canonical GM level.

[31] The power spectrum is marked not only by one broad peak close to the inertial frequency, but also by two sharp peaks at daily and near semidiurnal periods. These two peaks are associated with internal tides whose analysis will be detailed in Y. Cuypers et al. (Internal tides during Cirene
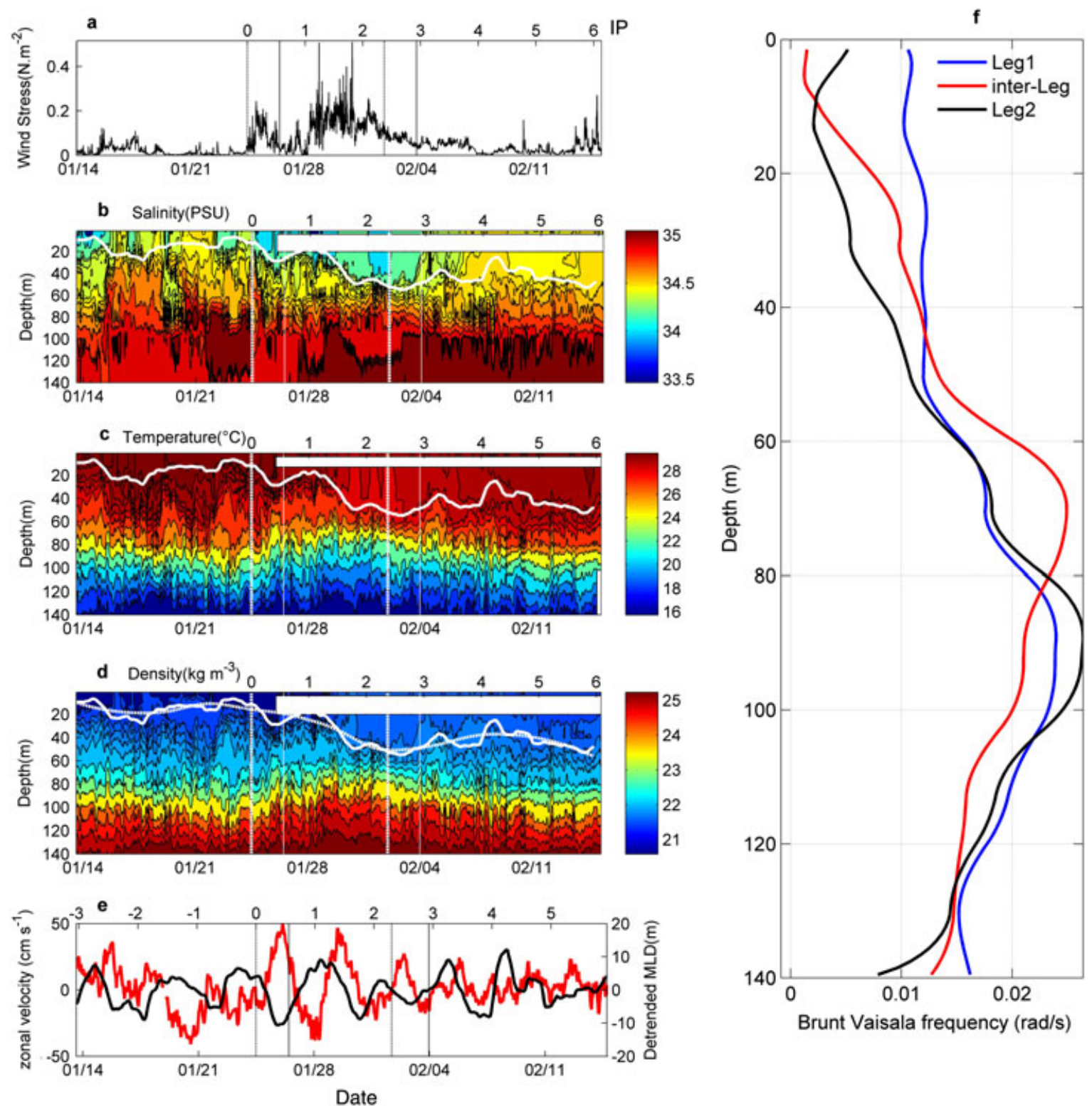

Brunt Vaisala frequency $(\mathrm{rad} / \mathrm{s})$

Figure 4. (a) Wind stress, (b) density anomaly, (c) temperature, (d) salinity, (e) mixed layer depth from which a nonlinear trend (white dashed line in Figure 4d) has been substracted (black) and zonal velocity at $26 \mathrm{~m}$ depth (red), and (f) leg and interleg averaged Brunt Vaisala frequency. All fields are at the ATLAS mooring location $\left(8^{\circ} \mathrm{S}, 67^{\circ} \mathrm{E}\right)$. The thick white line represents the mixed layer depth. The vertical dashed lines indicate the beginning and end of the "cyclone period" and the plain vertical lines delimit the interleg period. The time axis below each plot indicates the dates, while the time axis above the plots indicates the number of inertial periods after the first eyewall passage (e.g., after 24 January 2007). 
experiment, manuscript in preparation, 2013). We focus here on the peak at the inertial frequency.

[32] The energy content in the inertial frequency band strongly differs between the two periods. While the inertial peak is strongly marked at most depths during the post-cyclone period, it is not clearly apparent during the pre-cyclone period, especially below $200 \mathrm{~m}$ depth where it is hardly distinguishable (Figures 6a and 6b). This result is in agreement with the general observations of the previous section, indicating that NIW were generated during the passage of Dora.

[33] The NIW are clearly seen at most depths during the post-cyclone period. There is however no noticeable peak
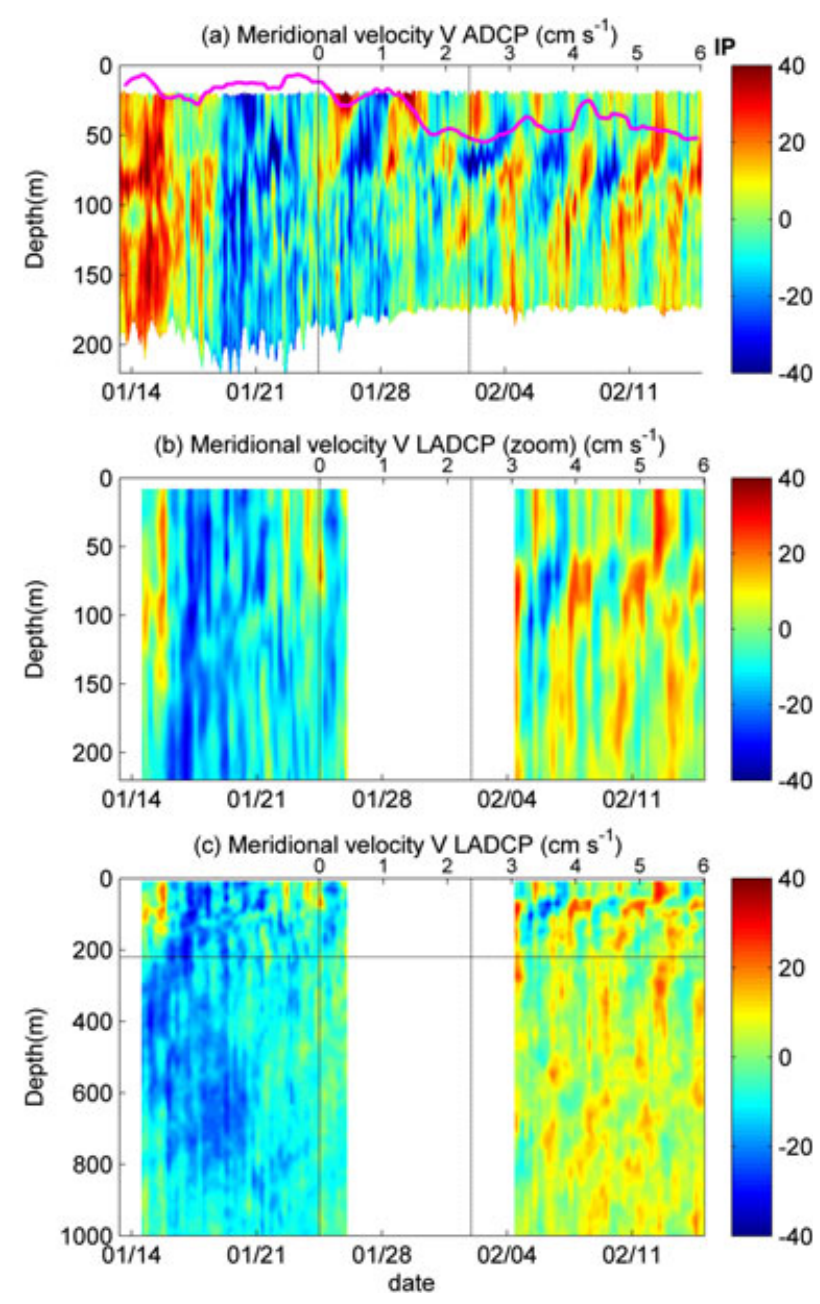

Figure 5. Meridional velocity from the (a) ADCP at the ATLAS mooring (the mixed layer depth is indicated by the magenta line), (b) LADCP at the FP station $\left(8^{\circ} \mathrm{S}, 67^{\circ} 30^{\prime} \mathrm{E}\right)$, zoomed over the top $220 \mathrm{~m}$ (same depth range as in Figure 5a), and (c) same as Figure 5b but for the full depth range of the LADCP. The time axis below each plot indicates the dates, while the time axis above the plots indicates the number of inertial periods after the first eyewall passage (e.g., after 24 January 2007). The ADCP mooring provides currents in the upper $200 \mathrm{~m}$ at a high sampling rate (Figure 5a), while the lowered ADCP provides currents down to $1000 \mathrm{~m}$ with a profile approximately every $6 \mathrm{~h}$ (Figures $5 \mathrm{~b}$ and $5 \mathrm{c}$ ). The dashed horizontal line on Figure $5 \mathrm{c}$ indicates the lower limit of the plotting range of Figures $5 \mathrm{a}$ and $5 \mathrm{~b}$. at near-inertial frequency at depths of 520 and $850 \mathrm{~m}$. This suggests the presence of several distinct wave groups, which will be characterized in the next sections.

[34] The spectral peak is centered at the inertial frequency $f$ at $8^{\circ} \mathrm{S}(f \pm 0.05 f$ for $\mathrm{ADCP}$ and $f \pm 0.15 f$ for LADCP) in the upper $70 \mathrm{~m}$ and at a super-inertial frequency $(1.2 f \pm 0.05 f$ for $\mathrm{ADCP}$ and $1.2 f \pm 0.15 f$ for LADCP) below. We will refer hereafter to $\omega_{0}=1.2 f$ as the observed near-inertial frequency.

(a) KE spectra mooring

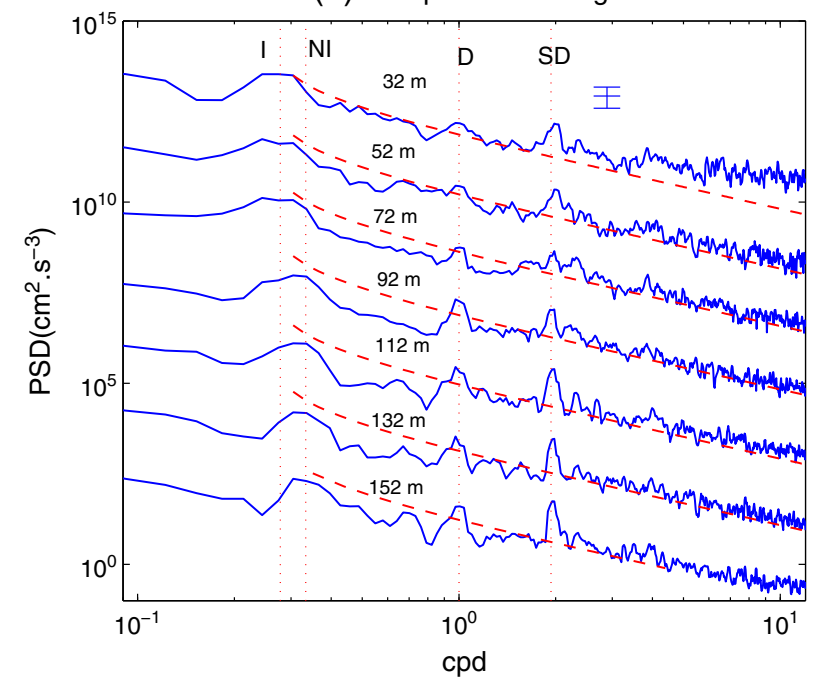

(b) KE spectra Leg1

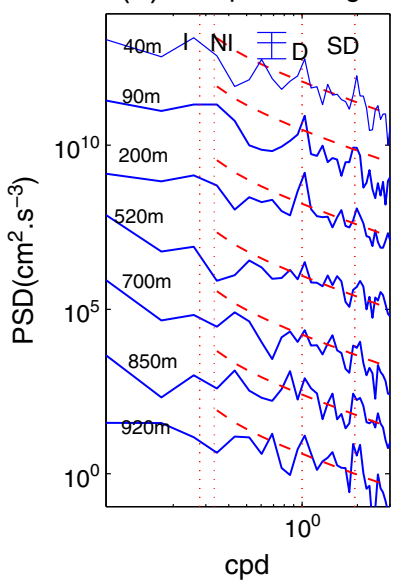

(c) KE spectra Leg2

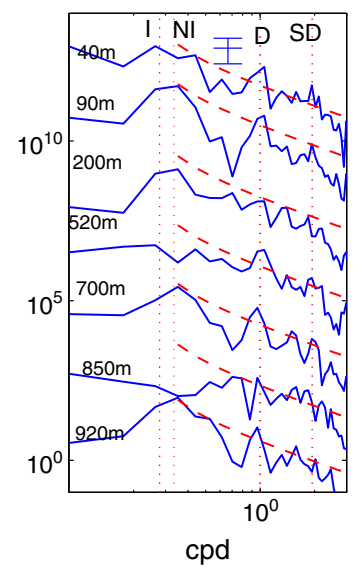

Figure 6. (a) Spectra of horizontal kinetic energy computed from ADCP measurements at the ATLAS mooring. The dashed lines show the Garret and Munk spectra. I, NI, D, and SD mark inertial (at $8^{\circ} \mathrm{S}$ ), near-inertial, diurnal, and semidiurnal frequencies. ( $b$ and c) Spectra of horizontal kinetic energy computed from LADCP at the FP station during leg 1 and leg 2 . The power spectra were computed every $4 \mathrm{~m}$ at depths ranging from 22 to $162 \mathrm{~m}$ for the ATLAS mooring ADCP data and every $8 \mathrm{~m}$ from 0 to $1000 \mathrm{~m}$ for the FP station LADCP data. Weighted ensemble averages of the spectra within $20 \mathrm{~m}$ vertical bins were then performed to reduce uncertainties. The $95 \%$ confidence interval is indicated on the plot. Note that for clarity, a vertical shit of 1.7 decade was applied between each spectrum. 


\subsection{Near-Inertial Internal Waves Characteristics}

\subsubsection{Methods}

[35] For linear internal waves of the form $\exp \left(i\left(\omega_{i} t-k_{x} x-\right.\right.$ $\left.k_{y} y-m z\right)$ ), where $\omega_{i}$ is the frequency, $k_{x}$ and $k_{y}$ the horizontal wave numbers, and $m$ the vertical wave number, propagating in an ocean with constant $N^{2}$ stratification, the dispersion relationship reads:

$$
\omega_{i}^{2}=f_{\mathrm{eff}}^{2}+N^{2} k_{h}^{2} /\left(k_{h}^{2}+m^{2}\right)
$$

where $f_{\text {eff }}$ is the effective inertial frequency that takes into account the vertical vorticity $\zeta$ of sub-inertial motions [Kunze, 1985], $f_{\text {eff }}=f+\zeta / 2$ with $\zeta=\frac{\partial v}{\partial x}-\frac{\partial u}{\partial y}$ and $k_{h}=$ $\sqrt{k_{x}^{2}+k_{y}^{2}}$. Such internal waves will propagate energy with a group velocity

$$
\begin{aligned}
& c_{g z}=-\left(N^{2}-f^{2}\right) \beta^{3} /\left(k_{h}\left(1+\beta^{2}\right)^{3 / 2}\left(f^{2}+N^{2} \beta^{2}\right)^{1 / 2}\right) \\
& c_{g h}=-\beta^{-1} c_{g z}
\end{aligned}
$$

with $\beta=k_{h} / m$ the angle of propagation to the vertical.

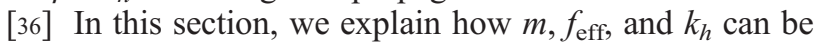
estimated from the velocity data obtained from the LADCP and the ADCP mooring, and how the group velocity is eventually determined. Before explaining the details, we summarize the main steps of our method:

[37] 1. We analyze for velocity field data with upward phase propagation, which allows identification of wave groups and estimation of their vertical wave number $m$.
[38] 2. We then estimate the effective inertial frequency $f_{\text {eff }}$ and the NIW intrinsic frequency $f$ following the method proposed by Alford and Gregg [2001], using the ratio of near-inertial kinetic and potential energy to estimate those quantities.

[39] 3. We can then determine the horizontal wave number $k_{h}$ from the dispersion relation (1).

[40] 4. Vertical $\left(c_{g z}\right)$ and horizontal $\left(c_{g h}\right)$ group velocities are finally obtained from (2).

[41] While the last two steps (c and d) are straightforward, the first two steps require more detailed explanations, which are given below:

\subsubsection{Estimation of the Vertical Wave Number}

[42] The vertical wave number is estimated first. A classical way to extract NIW propagation based on the downward energy propagation is to select current component showing an anticyclonic rotation with depth [Leaman, 1976]. This decomposition is however limited to the current field and cannot be applied to a scalar field (e.g., density fluctuations), which prevents an accurate determination of the downwardpropagating energy. Instead we separate velocity fields $\mathbf{U}(z, t)$ into $\mathbf{U}_{\mathbf{u p}}(z, t)$ with upward phase propagation $(m-\omega t)$ and $\mathbf{U}_{\text {down }}(z, t)$ with downward phase propagation $(m+\omega t)$ using a two-dimensional Fourier filter. This decomposition is also applied later to density fluctuations for the computation of the downward energy flux (section 3.3).

[43] The result of this decomposition is presented in Figure 7 for the meridional component of the LADCP velocity field.

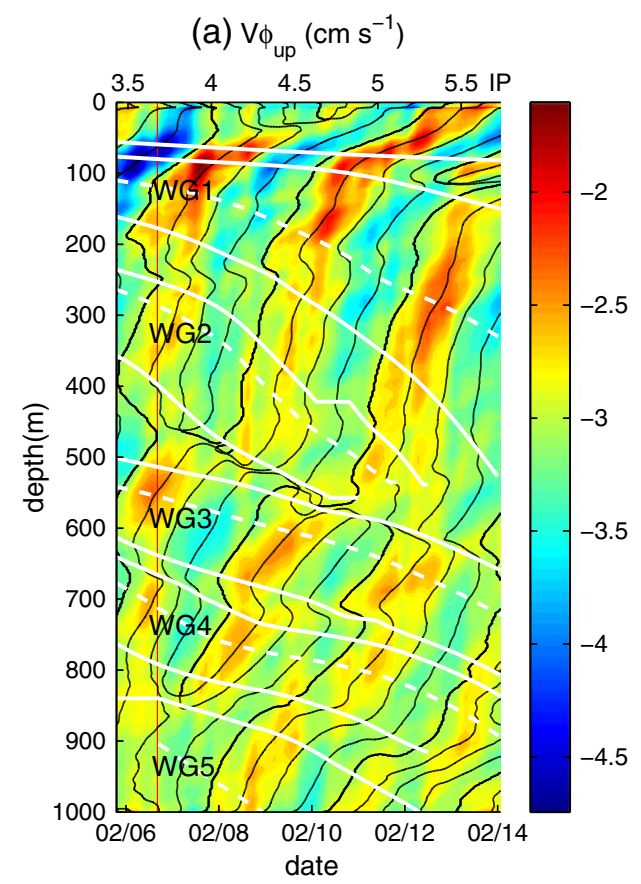

(b) $\mathrm{V}_{\text {down }}\left(\mathrm{cm} \mathrm{s}^{-1}\right)$

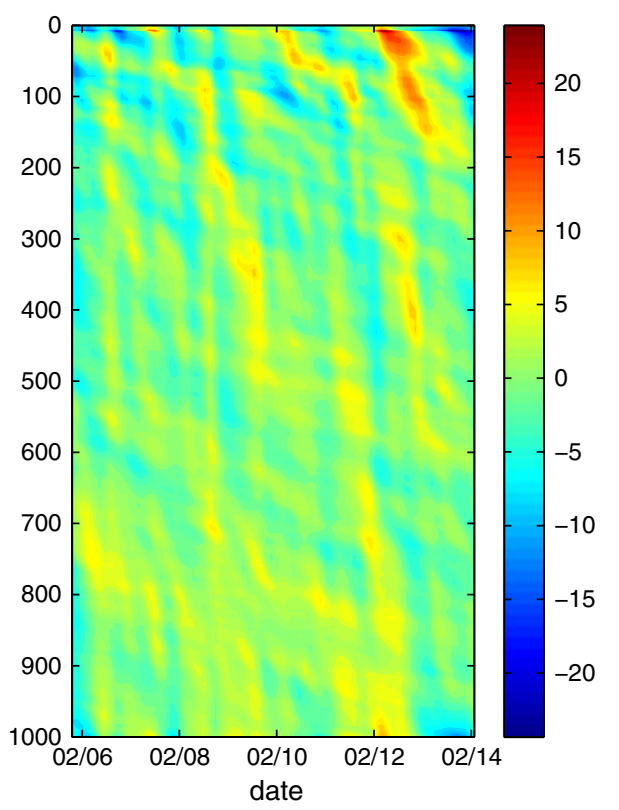

Figure 7. The FP station LADCP meridional velocity component during leg 2 separated in (a) upward $v_{\phi \text {,up }}$ and (b) downward $v_{\phi \text {,down }}$ phase propagation; black lines represent line of constant phase obtained after complex demodulation of rotary current $\mathbf{U}_{\boldsymbol{\phi} \text {, up }}=u_{\phi \text {, up }}+i v_{\phi \text {, up }}$, whereas whites lines represent rays trajectories computed from the vertical group velocity (see text for details). The time axis below Figure 7a indicates the dates, while the time axis above indicates the number of inertial periods after the first eyewall passage (e.g., after 24 January 2007). The red vertical line on Figure 7a corresponds to the date for which vertical profiles are displayed in Figure 9. 
Time-dependent amplitude and phase of near-inertial currents are estimated by applying a complex demodulation [Perkins, 1970] to $\mathbf{U}_{\mathbf{u p}}(z, t)$ at the observed frequency $\omega_{0}$ of the wave (cf. section 3.1). The resulting phase profiles $\Phi_{\text {up }}(z, t)$ (see Figure 7a or the snapshot in Figure 8b) display segments with linear phase-depth relations, separated by abrupt phase changes. These phase breaks and the associated amplitude minima (Figures 7a, 8a, and $8 \mathrm{~b})$ delimit distinct wave groups. The detection of the distinct wave groups was automated using a free-knot spline algorithm [Schütze and Schwetlick, 1997]. The vertical wave number $m$ is estimated for each segment by fitting a linear relationship $\Phi_{\text {up }}(z)=m z$ to the phase profile. Below the base of the pycnocline $(120 \mathrm{~m}$ depth), this fit is performed in WKB stretched vertical coordinates, in order to account for refraction resulting from the slow variation of $N$ with depth (see for instance Qi et al. [1995]). The WKB approximation is valid when the variation of $N$ over one vertical wavelength is slow enough to consider that properties of the wave depend only on the local value of $N$. Between the base of the pycnocline $(120 \mathrm{~m}$ depth) and the base of the mixed layer (30-40 $\mathrm{m}$ depth), the large variation of $N$ prevents the use of the WKB approximation, so instead we approximate there the stratification $N(z)$ over one section by its average over this section. Accordingly we fit the phase profile in linear coordinates. Fits were rejected in both cases when the square correlation coefficient between the fit and the phase profile was smaller than an arbitrary threshold value of 0.8 . Uncertainty in the $m$ estimate was finally established from $95 \%$ confidence intervals on the linear fit.

\subsubsection{Estimation of the Intrinsic Frequency}

[44] The following step is the estimation of the intrinsic frequency $\omega_{I}$ and effective inertial $f_{\text {eff. }}$ In addition to the dispersion relation (1), two relations are used: the first relates the intrinsic frequency of the wave to the observed frequency $\omega_{0}$ through a Doppler shift by the mean current:

$$
\omega_{i}=\omega_{0}+\left|k_{h}\right||\mathbf{U}| \cos (\theta-\alpha)
$$

where $|\mathbf{U}|$ is the mean current velocity and $\alpha$ is the angle between the mean current $\mathbf{U}$ and latitude circles and $\theta$ is the angle of propagation of NIWs in the horizontal plane. The second relates the ratio $r=\omega_{i} / f_{\text {eff }}$ to the near-inertial kinetic and potential energy as

$$
r=\omega_{i} / f_{\text {eff }}=[(R+1) /(R-1)]^{1 / 2}
$$

where $R$ is the ratio of near-inertial kinetic energy to available near-inertial potential energy [Fofonoff, 1969; Alford and Gregg, 2001]. Combining (1), (3), and (4), the effective inertial frequency becomes

$$
f_{\text {eff }}=\omega_{0} /\left[r+(m|\mathbf{U}| \cos (\theta-\alpha) / N)\left(r^{2}-1\right)^{1 / 2}\right]
$$

[45] Determination of intrinsic frequency horizontal wave numbers and group velocities then follows from (1), (2), and (4).

[46] The observed frequency is determined from the spectral analysis (section 3.1), and the vertical wave number $m$ is known from previous step (a), but several parameters of these relationships have still to be determined from the experimental measurements. $|\mathbf{U}|$ and
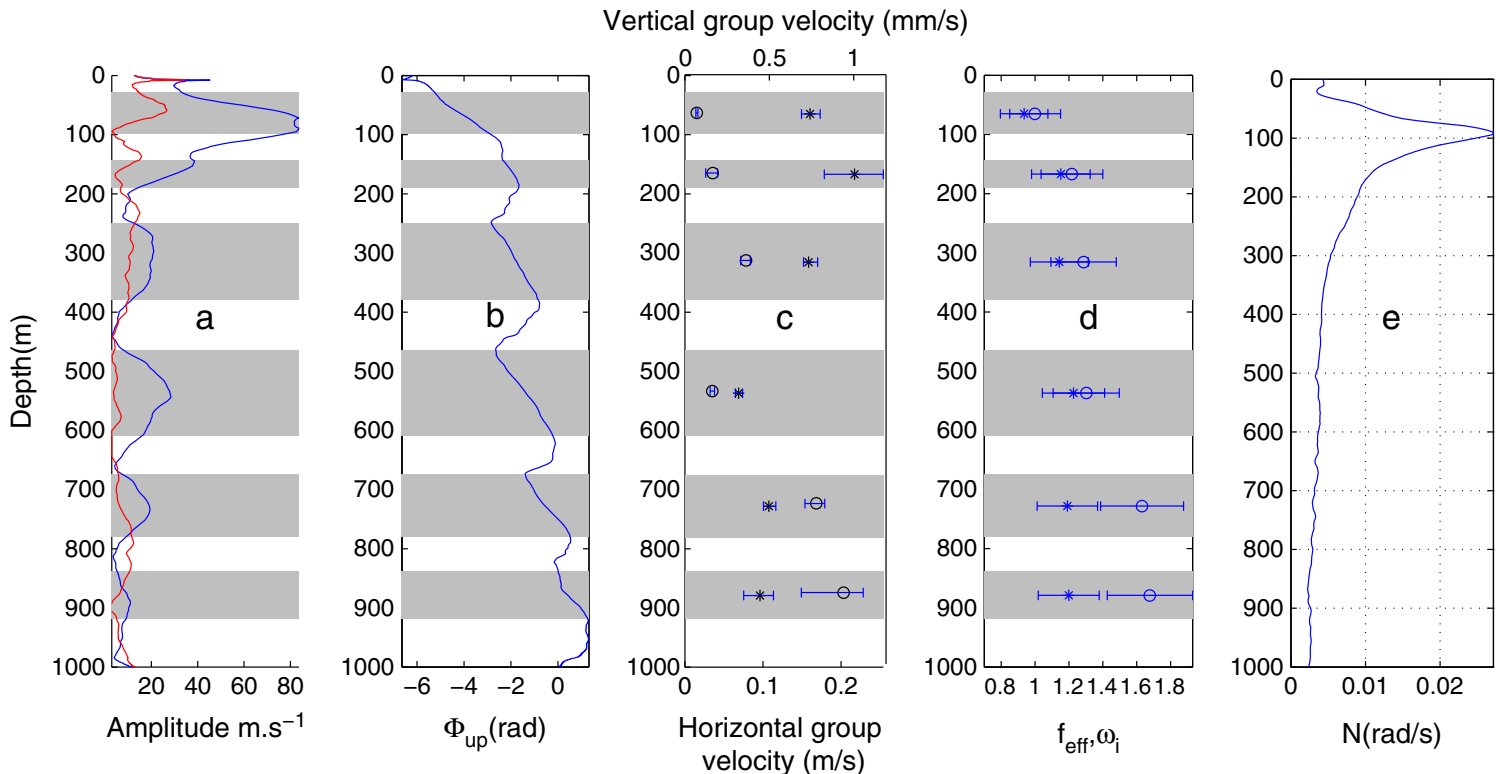

Figure 8. Wave groups characteristics as computed from FP station LADCP measurements during leg 2 around $t=3.7$ IP. (a) Demodulated near-inertial velocity amplitude with upward (blue) and downward (red) phase propagation component, (b) phase profile of the upward phase component, and (c) vertical group velocity indicated by circles and horizontal group velocity indicated by asterisks for each bin, and shaded areas represent depth bins over which the group velocity is computed. (d) Effective inertial frequency indicated by asterisks and intrinsic inertial frequency indicated by circles for each depth bin and horizontal bars represent the error bars, and (e) average stratification profile during post-cyclone phase. 


\section{CUYPERS ET AL.: STORM-INDUCED NIW DURING CIRENE}

$\alpha$ are estimated from an average over the entire leg 2 LADCP record. The wave number orientation $\theta$ is determined from polarization relationships by characterizing the phase lag between near-inertial upward-propagating zonal velocity fluctuations and near-inertial upward-propagating density fluctuations. A similar method was applied by Alford and Gregg [2001] using near-inertial shear and strain. Note that we estimate here this phase lag locally in time from the phase of the Morlet cross-wavelet transform [Torrence and Compo, 1998] at the near-inertial period between zonal velocity and density. The angle $\theta$ is a useful characterization of the wave group, since it gives indications about where the wave comes from. The kinetic and potential energy at near inertial periods are estimated as $\frac{1}{2} \rho_{0}\left(\frac{g \rho_{u p}{ }^{\prime}}{\rho_{0}}\right)^{2}$ and $\frac{1}{2} \rho_{0}\left(u_{u p}^{\prime}{ }^{2}+v_{u p}^{\prime}{ }^{2}\right)$, respectively, $\rho_{0}$ a constant density set to $1025 \mathrm{~kg} \mathrm{~m}^{-3}, \rho_{\text {up }}{ }^{\prime}, u_{\text {up }}{ }^{\prime}$, and $v_{\text {up }}{ }^{\prime}$ being the upward-propagating component of velocity and density fluctuations at near-inertial period (we used an elliptical filter [Park and Burrus, 1987] in a band [0.7 $\left.\left.\omega_{0}, 1.4 \omega_{0}\right]\right)$. The $R$ ratio is further obtained from a running mean of those near-inertial potential and kinetic energy over one near-inertial observed period $\left(2 \pi / \omega_{0}\right)$. Error bars for $f_{\text {eff }}, \omega_{I}$, and the group velocities were estimated from both the $95 \%$ confidence interval on the wave number $m$ and the spectral resolution $(0.05 f$ for the ATLAS mooring and $0.15 f$ for the LADCP data).

[47] A side product of this computation is also an estimation of the background vorticity as $\zeta / 2=f-f_{\text {eff. }}$. In order to see if our approach is valid, we have tried to compare the values obtained by the method above to independent background surface vorticity values obtained from OSCAR surface currents (Figure 9). The effective inertial frequency found from FP station measurements in the surface layer is slightly sub-inertial (of the order of $0.95 f$ ) for most of the second leg period (Figure 7 and Table 1). This suggests that the upper layer surface background vorticity field is mostly slightly anticyclonic $\zeta \sim-0.05 f$. These estimates are consistent with the large-scale $\left(1^{\circ}\right.$ resolution) and sub-inertial (5 day resolution) surface vorticity estimates inferred from OSCAR data (Figure 9). Those data suggest a negative background vorticity in the Cirene area during the passage of Dora and the period of baroclinic wave generation (of the order of $-0.03 f$ ) for most of the second leg period,

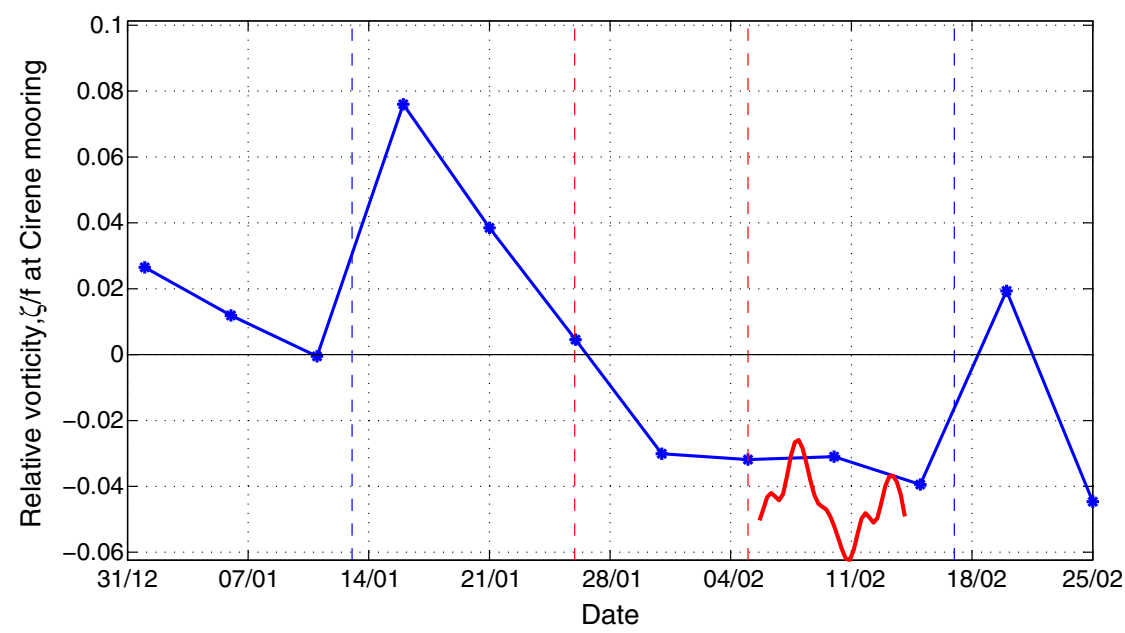

Figure 9. Time series of relative vorticity at the FP station, from the OSCAR surface velocity product in blue and estimated from FP station measurements in red. Blue dashed vertical lines indicate the beginning and end dates of the measurements, and the red dashed vertical lines correspond to the passage of DORA and baroclinic wave generation.

Table 1. The WG Mean Properties in Average Depth Ranges ${ }^{\mathrm{a}}$

\begin{tabular}{|c|c|c|c|c|c|c|c|}
\hline $\begin{array}{l}\text { Wave Group and Depth } \\
\text { Interval (m) }\end{array}$ & $f_{\text {eff }} / f$ & $\omega_{i} / f$ & $\lambda_{z}(\mathrm{~m})$ & $\lambda_{h}(\mathrm{~km})$ & $c_{g z}\left(\mathrm{md}^{-1}\right)$ & $c_{g h}\left(\mathrm{~m} \mathrm{~s}^{-1}\right)$ & Propagation Angle to East \\
\hline WG1 [30-100] & [0.93-1.0] & [1-1.02] & [90-160] & {$[250-500]$} & {$[2-5]$} & {$[0.07-0.14]$} & [70-150] \\
\hline WG1m [30-100] & {$[0.87-0.92]$} & {$[0.96-0.98]$} & {$[100-140]$} & {$[250-350]$} & {$[2-5]$} & {$[0.06-0.12]^{*}$} & {$[110-180]^{*}$} \\
\hline WG1 [100-200] & {$[1.0-1.15]$} & {$[1.18-1.25]$} & $\begin{array}{l}{[200-500]} \\
{[800-1200]^{*}}\end{array}$ & $\begin{array}{l}{[250-550]} \\
{[800-2000]^{*}}\end{array}$ & {$[10-40]$} & {$[0.25-0.4]$} & {$[50-150]$} \\
\hline WG1-2 [230-450] & {$[1.05-1.12]$} & {$[1.2-1.3]$} & $\begin{array}{l}{[300-750]} \\
{[500-700]^{*}}\end{array}$ & $\begin{array}{l}{[180-300]} \\
{[200-400]^{*}}\end{array}$ & {$[30-100]$} & {$[0.15-0.3]$} & {$[50-100]$} \\
\hline WG3 [500-700] & {$[1.05-1.2]$} & {$[1.2-1.35]$} & $\begin{array}{l}{[220-380]} \\
{[150-250]^{*}}\end{array}$ & $\begin{array}{l}{[50-130]} \\
{[40-100]^{*}}\end{array}$ & {$[10-40]$} & {$[0.05-0.1]$} & {$[260-330]$} \\
\hline WG4 [680-850] & {$[1.05-1.2]$} & {$[1.25-1.6]$} & $\begin{array}{l}{[200-350]} \\
{[120-200]^{*}}\end{array}$ & $\begin{array}{l}{[50-90]} \\
{[30-50]^{*}}\end{array}$ & {$[8-60]$} & {$[0.04-0.12]$} & {$[100-200]$} \\
\hline WG5 [850-1000] & [1-1.05] & [1.15-1.6] & $\begin{array}{l}{[250-600]} \\
{[150-300]^{*}}\end{array}$ & $\begin{array}{l}{[35-75]} \\
{[30-50]^{*}}\end{array}$ & {$[40-90]$} & {$[0.06-0.15]$} & {$[250-350]$} \\
\hline
\end{tabular}

\footnotetext{
${ }^{\mathrm{a}}$ Indicated in brackets in the left column, estimated from in situ data. The WG characteristics are in general estimated from FP station profiles during leg 2 , except WG1 in the 30-100 $\mathrm{m}$ range for which estimates from the ATLAS mooring (labeled WG1m) are also provided for the leg 2 period. Asterisks indicate the wavelength in WKB coordinates.
} 
namely an effective inertial frequency of the order of $0.97 f$. This shift is slightly smaller than our estimates, but still provides an independent consistency test of our approach.

\subsubsection{Identified Wave Groups and Their Characteristics}

[48] Figure 7 shows the upward and downward propagating components of the meridional velocity from the Fixed Point station. As expected, the upward phase component of near-inertial velocity signal is dominant (Figures $7 \mathrm{a}, 7 \mathrm{~b}$, and 8a). Evidence of NIW with downward group velocity can be found down to $1000 \mathrm{~m}$ with significant amplitude of $\sim 10 \mathrm{~cm} \mathrm{~s}^{-1}$ (Figure 7a). This suggests that a significant fraction of NIW energy generated in the surface layer is potentially available for mixing at depth.

[49] Examination of Figure 7 also suggests propagation of several distinct wave groups. At the beginning of the postcyclone period, as many as five wave groups can be identified, the first one (WG1), generated after Dora's passage over the FP station and ATLAS mooring area, propagates from the base of the pycnocline down to $500 \mathrm{~m}$ depth, whereas a second less energetic wave group (WG2) appears at roughly $250 \mathrm{~m}$ depth and propagates downward. These two wave groups seem to merge around 10 February where their phase becomes indistinguishable below $300 \mathrm{~m}$ depth. A third (WG3) and fourth (WG4) wave group propagate respectively from 500 to $700 \mathrm{~m}$ depth and from 680 to $850 \mathrm{~m}$ depth. Finally, a last wave group (WG5) can be identified propagating from 850 to $1000 \mathrm{~m}$ depth and can be tracked until 9 February when it extends below the depth of the LADCP data.

[50] To better illustrate those wave groups and check the consistency of our vertical wave group estimate, we have computed near-inertial way ray trajectories $z(t)$ on the depth-time space as

$$
z(t)=z\left(t_{0}\right)+\int_{t_{0}}^{t} C_{g z}\left(t^{\prime}, z\left(t^{\prime}\right)\right) d t^{\prime}
$$

[51] A few trajectories were superimposed on Figure 7 to delimit the deepening of the wave groups with time (for those trajectories, initial positions $z\left(t_{0}\right)$ were chosen at the edges of regions with a linear phase change). Good agreement is found between the regions of extreme velocity fluctuations associated with the wave groups and the ray trajectories. The strong variation of $c_{g z}$ in the pycnocline region ( $90 \mathrm{~m}$ depth) results in a divergence of ray beams generated there. This explains the widening of the first wave group with time as well as the splitting of this wave group that seems to be observed around $100 \mathrm{~m}$ depth by the end of the post-cyclone period since a part of the energy remained trapped at the top of the pycnocline.

[52] The wave groups can also be clearly identified on Figures $8 \mathrm{a}$ and $8 \mathrm{~b}$ showing amplitude and phase of the near-inertial current at the beginning of the post-cyclone period (morning of 6 February, 3.7 inertial periods after the first wind burst). Indeed the separation between each wave group is associated with an amplitude minima and a phase break.

[53] The range of the characteristics of each wave group during the post-cyclone period is summarized in Table 1 . The first wave group generated by Dora is characterized by a small vertical group velocity of a few $\mathrm{md}^{-1}$ in the first $100 \mathrm{~m}$ depth. The associated horizontal and vertical wavelengths are respectively in the range $250-500 \mathrm{~km}$ and $90-160 \mathrm{~m}$. Good agreement is found between the independent estimates at the ATLAS mooring and FP station for these quantities. The relatively large spatial scale $(250-500 \mathrm{~km})$ of the first wave group (WG1) is probably related to the spatial scale of the forcing itself. At this early stage of the cyclogenesis, the eyewall (typically $\sim 25-50 \mathrm{~km}$ size) is not formed yet, and winds vary at larger $\sim 500 \mathrm{~km}$ spatial scale (Figure 2). A similar range of values was found for an NIW at $6^{\circ} \mathrm{S}$ in the Banda Sea of Indonesia by Alford and Gregg [2001].

[54] Noticeable features are also the relatively small vertical and horizontal wavelengths for the waves in the third, fourth, and fifth groups propagating below $500 \mathrm{~m}$ depth (Table 1). This is striking when the wavelengths of each wave group are corrected from the effect of diffraction using WKB scaling: horizontal and vertical wavelengths of WG3-WG5 are then respectively about 10 times and five times smaller than horizontal and vertical wavelengths of WG1. A low vertical group velocity is found for these wave groups, which is consistent with (2) if a constant propagation angle $\boldsymbol{\beta}$ to the vertical is assumed.

[55] Once the characteristics of the wave packets are determined, the vertical group velocity is computed and energy fluxes are derived (see section 3.1)

\subsubsection{Vertical Mode Approach}

[56] Vertically propagating internal waves can be described either as a sum of standing vertical modes or as a ray beam [Gerkema and Zimmerman, 2008]. Several theoretical, experimental, and numerical studies [Pollard, 1970; Gill, 1984; Shay et al., 1989] have used vertical mode decomposition to infer the rate of energy escaping the mixed layer under the form of NIW. Here we have chosen the wave ray approach because most measurements are limited to the first $1000 \mathrm{~m}$ and projection on vertical modes cannot be achieved over the full depth range. It is however possible to compute the vertical mode structures and eigenvalues [Gill 1982] using the $N^{2}$ profile corresponding to the averaged CTD profiles over the top $500 \mathrm{~m}$ during the legs and extended down to the bottom using the World Ocean Data Base 2009 climatology. The vertical modes structures of displacements $W_{n}$ and phase speed $c_{n}$ are the eigenfunctions and eigenvalues of the Sturm-Liouville problem:

$$
\frac{d^{2} W_{n}}{d z^{2}}+\frac{N^{2}}{c_{n}^{2}} W_{n}=0
$$

[57] The vertical modes of velocity $P_{n}$ can be obtained from the vertical derivative of $W_{n}$. The first five vertical modes $P_{1-5}$ are presented in Figure $10 \mathrm{~b}$ and $c_{n}$ values are reported in Table 2 . The rate of inertial energy escaping the mixed layer is set by the ratio of the storm horizontal scale $2 R_{\max }$ to the Rossby radius for the first vertical mode, $f / k_{h} c_{1}$, where $c_{1}$ is the first eigenmode phase speed and $k_{h}=$ $\pi /\left(2 R_{\max }\right)$ is a horizontal wave number associated with inertial currents in the mixed layer. For $f / k_{h} c_{1} \gg 1$ (largescale forcing typical of synoptic disturbances), inertial currents remain trapped in the mixed layer; whereas for $f / k_{h} c_{1} \sim 1$ (small-scale forcing associated with hurricanes) energy is radiated from the mixed layer in a few inertial periods [Gill, 1984]. 

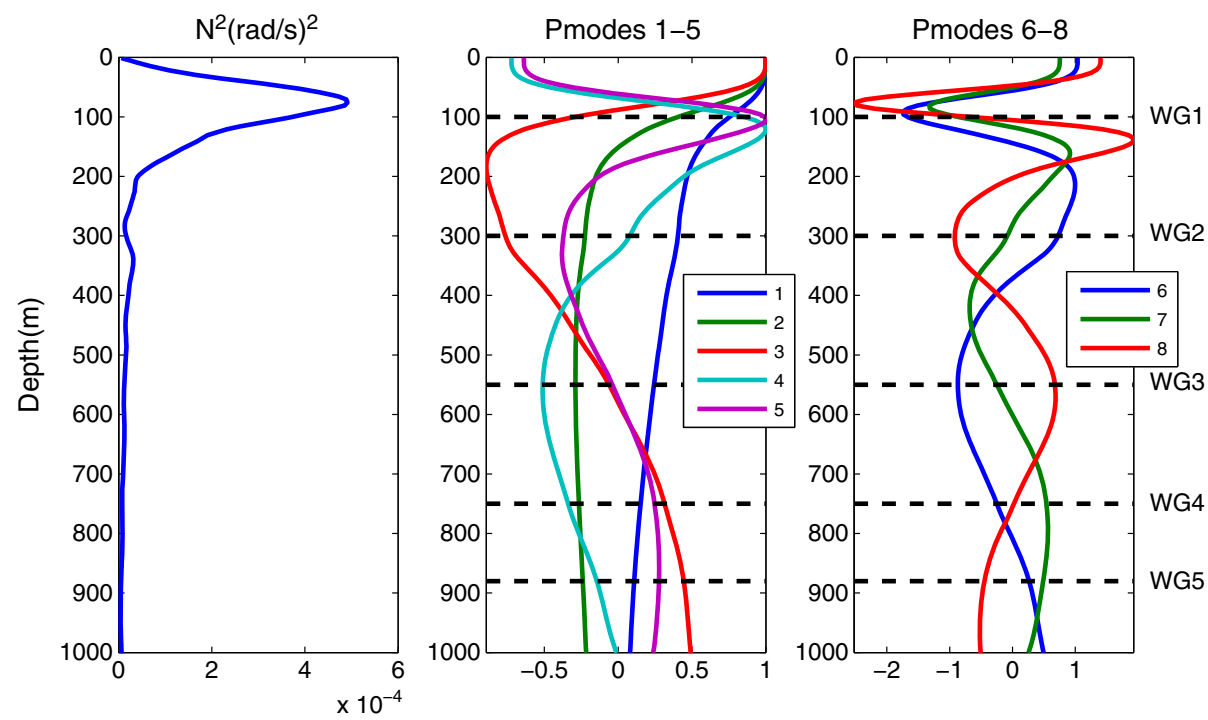

Figure 10. Buoyancy profile corresponding to the (a) averaged CTD profiles over the top $500 \mathrm{~m}$ and extended below using the World Ocean Data Base 2009 climatology and corresponding horizontal velocity modes (b) $\mathrm{P}(1-5)$ and (c) $\mathrm{P}(6-8)$. The figure shows the first $1000 \mathrm{~m}$ only. Black dashed lines show the positions of maximum demodulated near-inertial velocity amplitude for the five wave groups around $t=3.7$ IP as depicted in Figure 8.

[58] On 28 February, the storm had not yet formed and the Météo France regional center in La Réunion provided no storm radius estimate. At this stage, the winds were however sufficiently weak to use QuikSCAT wind data to provide a rough estimate of $R \sim 100 \mathrm{~km}$ (Figures $2 \mathrm{~b}$ and $2 \mathrm{c}$ ). This leads to $f / k_{h} c_{1} \approx 0.49$, suggesting a rapid transfer of energy below the mixed layer. Following Gill [1984] and assuming that most of the energy is contained within the gravest vertical modes [Shay et al., 1989], we can compute an estimate of the typical time for energy transfer below the mixed layer. This is given by $t_{n}=\pi /\left(2\left(\omega_{n}-f\right)\right.$, where $\omega_{n}=$ $\sqrt{f^{2}+k_{h}^{2} c_{n}^{2}}$. Table 3 gives the estimate of this time scale for the first five modes, which is in the range of $0.2-2.5$ inertial periods. This is in qualitative agreement with the appearance of near-inertial currents in the pycnocline after

Table 2. Budget of Heating (in ${ }^{\circ} \mathrm{C}$ month ${ }^{-1}$ ) Between Different Isopycnals $^{\mathrm{a}}$

\begin{tabular}{lccc}
\hline Interval & {$[22-23] \mathrm{kg} \mathrm{m}^{-3}$} & {$[23-24] \mathrm{kg} \mathrm{m}^{-3}$} & {$[24-25] \mathrm{kg} \mathrm{m}^{-3}$} \\
\hline Leg 1 & -0.13 & 0.06 & 0.08 \\
Inter-leg & -0.13 & 0.44 & 0.03 \\
Leg 2 & -0.26 & 0.42 & $0.27 \mathrm{C}$ \\
\hline
\end{tabular}

${ }^{\mathrm{a}}$ Just below the mixed layer $\left(22-23 \mathrm{~kg} / \mathrm{m}^{3}\right)$, within the pycnocline $\left(23-24 \mathrm{~kg} / \mathrm{m}^{3}\right)$, and below the pycnocline $\left(24-25 \mathrm{~kg} / \mathrm{m}^{3}\right)$. Averaged values during leg 1, the inter-leg period, and leg 2 are displayed. The leg 1 is characteristic of a period with little NIW breaking, while the leg 2, after the passage of the Dora storm, is characterized by intense NIW wave activity and associated mixing. two inertial periods (Figure 5a) and with the ray tracing showing the propagation of the NIW from the base of the mixed layer in about the same time. This suggests that Gill [1984] vertical mode approach is consistent with our results and that most of the energy of the first wave group generated by Dora is contained within the gravest in agreement with previous observations by Shay et al. [1989]. Deeper wave groups (WG2-WG5) generate near-inertial current local maxima well below the pycnocline (Figure 8a). These deeper maxima are likely associated with higher vertical modes (mode 6-8) as is shown in Figure 10c.

\subsection{Energy Fluxes}

[59] An important outcome of this study is the estimation of the fraction of wind power input to inertial motions that is transferred to the interior ocean by the energy flux of NIW. The downward vertical flux can be computed from vertical group velocity as $c_{g z}\left\langle E_{u p}\right\rangle_{T_{0}}$ where $E_{\text {up }}=$ $\frac{1}{2} \rho_{0}\left(\left(\frac{g \rho_{\text {up }}^{\prime}}{\rho_{0}}\right)^{2}+u_{\text {up }}^{\prime}{ }^{2}+v_{\text {up }}^{\prime}{ }^{2}\right)$ is the total energy of upward phase propagating NIWs, computed as indicated in section 3.2.1. The horizontal energy fluxes moduli are likewise estimated as $c_{g h}\left\langle E_{\text {up }}\right\rangle_{T_{0}}$ while its direction is given by the angle $\theta$ (section 3.2.1).

[60] Figures 11 and 12 show vertical energy flux computed for LADCP and ADCP data, respectively. Both show a local maximum in the pycnocline between 80 and $120 \mathrm{~m}$

Table 3. Phase Speed (c), Separation Time ( $t$ in IP), and Ratio of the Typical Cyclone Horizontal Forcing Length-Scale to the Rossby Radius $(f / k c)$ for the First Four Vertical Modes

\begin{tabular}{lrrr}
\hline$c_{1}=2.62 \mathrm{~m} \mathrm{~s}^{-1}$ & $c_{2}=1.65 \mathrm{~m} \mathrm{~s}^{-1}$ & $c_{3}=1.05 \mathrm{~m} \mathrm{~s}^{-1}$ & $c_{4}=0.71 \mathrm{~m} \mathrm{~s}^{-1}$ \\
$t_{1}=0.20 \mathrm{IP}$ & $t_{2}=0.40 \mathrm{IP}$ & $t_{3}=0.86 \mathrm{IP}$ & $t_{4}=1.74 \mathrm{IP}$ \\
$f / k_{h} c_{1}=0.49$ & $f / k_{h} c_{2}=0.78$ & $f / k_{h} c_{3}=1.22$ & $f / k_{h} c_{4}=1.8$ \\
\hline
\end{tabular}


(a) Vertical downward energy flux $\left(\mathrm{mW} \mathrm{m}^{-2}\right)$

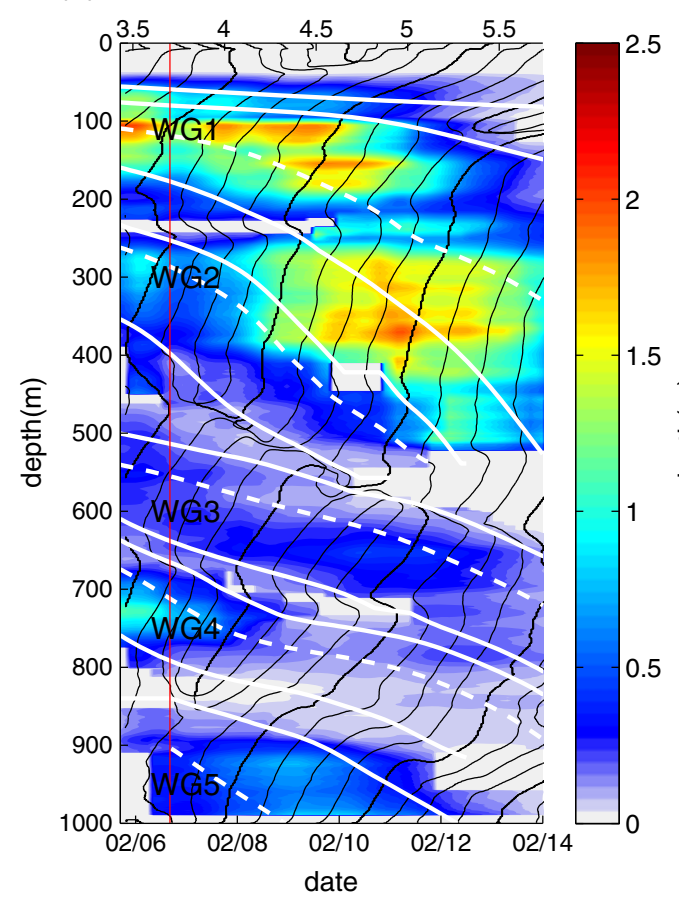

(b) Horizontal energy flux $\left(\log 10\left(\mathrm{~W} \mathrm{~m}^{-2}\right)\right)$

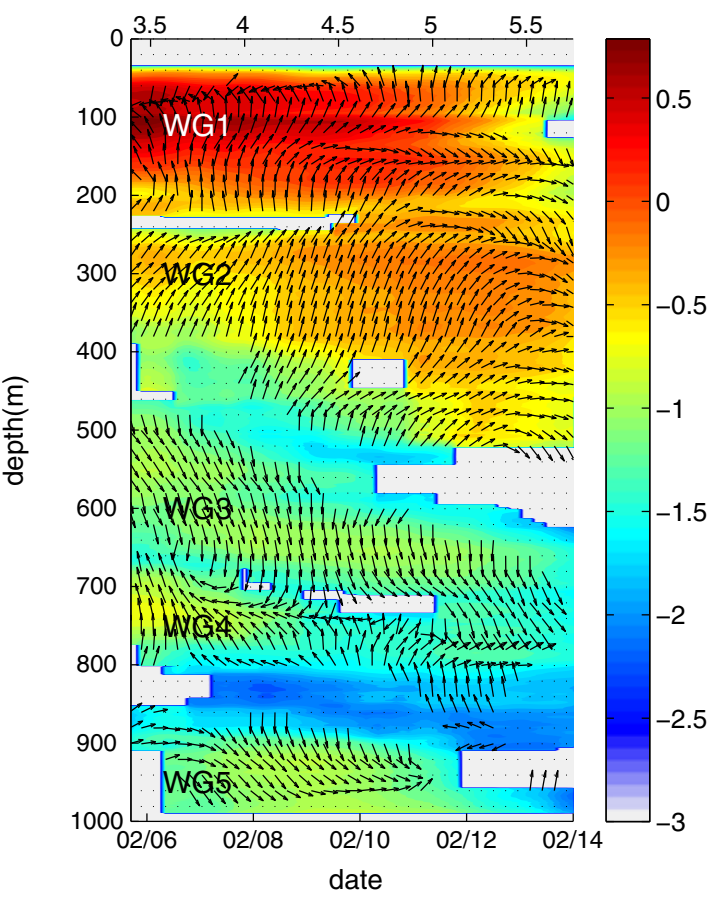

Figure 11. Energy fluxes computed from leg 2 LADCP data at the FP station. (a) Downward near-inertial energy flux (the magnitude is indicated by the color bar) and lines of constant inertial phase; whites lines represent rays trajectories computed form the vertical group velocity (see text for details), and black thin lines represent phases of complex demodulated near-inertial currents. (b) Decimal logarithm of horizontal near-inertial energy flux modulus (the magnitude is indicated by the color bar; the arrows represent the direction of propagation of the horizontal energy flux on an horizontal plane, with upward arrows for a northward energy flux and downward arrows for a southward energy flux). The time axis below each plot indicates the dates, while the time axis above the plots indicates the number of inertial periods after the first eyewall passage (e.g., after 24 January 2007).

depth resulting from Dora's passage with a maximum value of $\sim 2.5 \mathrm{~mW} \mathrm{~m}^{-2}$ is observed both at the FP station and at the ATLAS mooring. A broad maximum of the energy flux reaching $2 \mathrm{~mW} \mathrm{~m}^{-2}$ is also observed between 270 and $390 \mathrm{~m}$ depth, corresponding to the propagation of the second wave group and its merging with the first wave group by the end of the post-forcing period. At greater depth, the fourth and fifth wave groups are associated with downward energy flux reaching, respectively, 1 and $0.75 \mathrm{~mW} \mathrm{~m}^{-2}$ at 750 and $950 \mathrm{~m}$, showing that a significant fraction of NIW energy flux can reach large depths. The horizontal energy fluxes are three orders of magnitude larger (which reflects the typical ratio between horizontal and vertical scales in the ocean), but show a similar vertical structure.

[61] The direction of the horizontal energy flux also reflects the propagation direction of the NIW. The first wave group WG1 displays an average northward propagation at the depth of the pycnocline $(90 \mathrm{~m})$ at both FP station and at the ATLAS mooring during the post-cyclone period (Figures $11 \mathrm{~b}$ and $12 \mathrm{~b}$ ). The ATLAS mooring data however suggest a southward propagation of WG1 during the cyclone period, when the wave group was still located at the base of the mixed layer between 20 and $60 \mathrm{~m}$ depth, suggesting the NIW was generated to the north of the mooring. The change in the direction of propagation of the wave between pre-cyclone and post-cyclone period may result from its reflection at its critical latitude since it was propagating southward where $f$ increases. However as will be discussed in the last section, wave propagation can be largely affected by the mesoscale vorticity field in the region. It is therefore difficult to extrapolate wave propagation in the region from the single point data available in this study and we leave a more precise quantification of this process for a future modeling study. At greater depths, the direction of propagation clearly changes (Figure 11b) depending for some wave groups. An average northeastward propagation is found for the second wave group, southeastward for the third wave group, northwestward for the fourth wave group, and southeastward for the fifth wave group. We will further discuss the propagation of the wave groups in section 5 .

[62] It is interesting to compare the baroclinic energy flux associated with the first wave group with the wind power input as a kinetic energy per unit time in the mixed layer during Dora passage. As shown by Geisler [1970], the wind power input into the mixed layer associated with a storm or a hurricane depends on the ratio between the first vertical mode phase velocity $c_{1}$ and the hurricane displacement velocity $U_{h}$. Geisler considers two regimes $U_{h}>c_{1}$ for which the wind power input in the mixed layer per unit area $P_{i}$ reads $P_{i}=$ $\frac{1}{2} \rho_{0} U_{h} u_{s}{ }^{2}$ (where $u_{s}$ is the ageostrophic velocity modulus) 
(a) Vertical downward energy flux $\left.\left(\mathrm{mW} \mathrm{m}^{-2}\right)\right)$

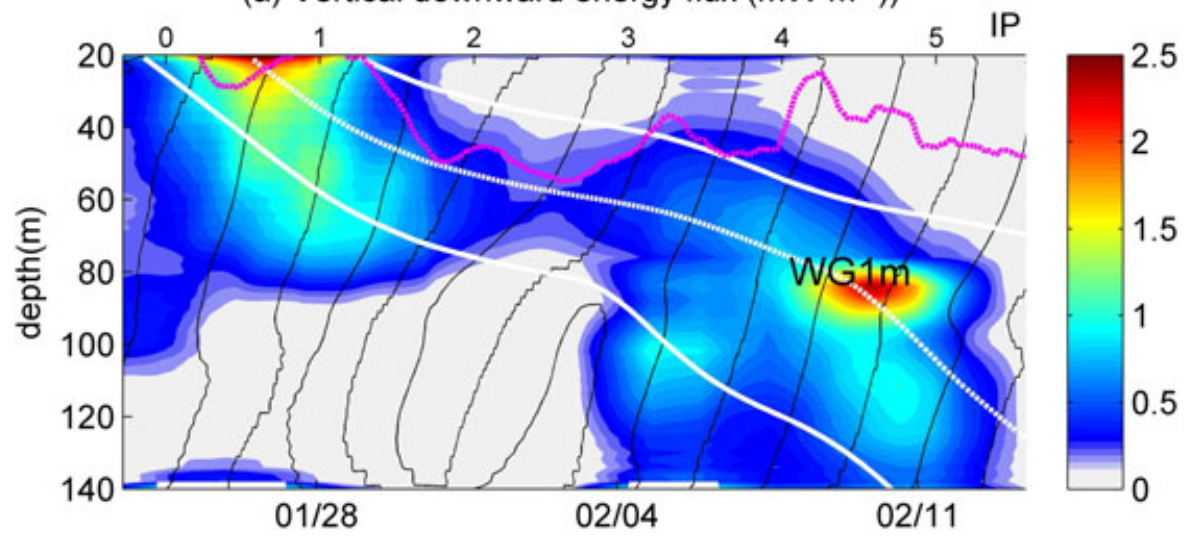

(b) Horizontal energy flux $\left(\mathrm{W} \mathrm{m}^{-2}\right)$

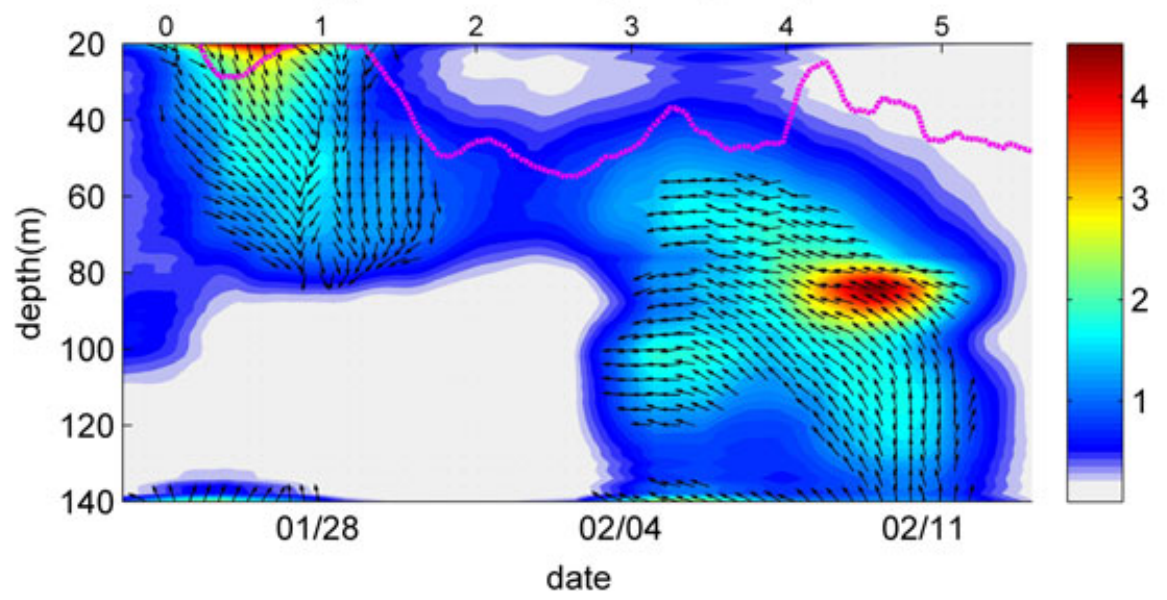

Figure 12. Energy fluxes computed from ADCP mooring data for the inter-leg and leg 2 period. (a) Downward near-inertial energy flux and lines of constant inertial phase; whites lines represent rays trajectories computed form the vertical group velocity (see text for details and magenta dashed line is the limit of the mixed layer). (b) Horizontal near-inertial energy flux; arrows represent direction of propagation of the horizontal energy flux on a horizontal plane. The time axis below each plot indicates the dates, while the time axis above the plots indicates the number of inertial periods after the first eyewall passage (e.g., after 24 January 2007).

and $U_{h}<c_{1}$ for which $P_{i}=\frac{1}{2} \rho_{0} u_{s}{ }^{3}$. In the case of Dora, $U_{h} \sim$ 2-4 $\mathrm{m} \mathrm{s}^{-1}$ (Figure 2e) and $c_{1}=2.7 \mathrm{~m} \mathrm{~s}^{-1}$, therefore we are in a marginal case where $U_{h} \sim c_{1}$ and we consider the values given by the two expressions. We estimate $u_{s}$ at the mooring as the velocity in the mixed layer from which we subtract geostrophic velocity $\left(U_{g}\right.$, estimated from a running average of the mixed layer velocity over one inertial period). This provides a large interval for maximum $P_{i}$ of $30-180 \mathrm{~W} \mathrm{~m}^{-2}$. The maximum of $P_{i}$ can be compared with the maximum horizontal NIW energy flux $F_{x}$ ( total since $C_{g x} \gg C_{g z}$ ) which reaches $6 \mathrm{~W} \mathrm{~m}^{-2}$ at the $\mathrm{FP}$ station with a $95 \%$ confidence interval of [5-10] $\mathrm{W} \mathrm{m}^{-2}$ and $5 \mathrm{~W} \mathrm{~m}^{-2}$ at the mooring with a $95 \%$ confidence interval of $4-6 \mathrm{~W} \mathrm{~m}^{-2}$. Considering the uncertainty in those estimates, there is a substantial uncertainty on the $F_{x} / P_{i}$ ratio, between $2 \%$ and $33 \%$.

[63] To complement the approach above, we also estimate the efficiency of the transfer to vertically propagating NIW from the ratio of the vertical NIW energy flux $F_{z}$ to the wind work onto surface currents namely $\boldsymbol{\tau} \mathbf{u}_{f}$ [see for instance
Von Storch et al., 2007; Furuichi et al., 2008] where $\mathbf{u}_{f}$ are inertial currents in the mixed layer estimated here as the ocean surface velocity filtered at the inertial frequency and $\tau$ the wind stress derived here from the ATLAS mooring meteorological data. Note that the computation of the wind work onto inertial currents may not provide a good estimation of the wind power input for a fast-moving cyclone for which the duration of the wind forcing is short compared to the setup of inertial currents. As explained before, the most intense wind forcing is quite long in the case discussed here ( 8 days) and inertial currents are generated in the mixed layer within the wind forcing period (Figure 6); therefore, we can expect that the wind work onto inertial currents will provide a reasonable alternative estimate of the local wind power input. The value of $\boldsymbol{\tau} \mathbf{u}_{f}$ can change sign depending on whether the wind works with or against inertial currents. Strongest maxima and minima of $\boldsymbol{\tau} \mathbf{u}_{f}$ are observed alternatively at the inertial period during 10 days starting from 25 January (Figure 11a). A maximum 
positive power input of $30 \mathrm{~mW} \mathrm{~m}^{-2}$ is reached two times, first on 28 January (when Dora was closest to the mooring) and a second time on 1 February with a minimum of -35 $\mathrm{mW} \mathrm{m}{ }^{-2}$ in between. It is difficult to provide a quantitatively precise estimate of the fraction of the energy input that penetrates to the deep ocean from observations at a single location. It is however interesting to note that the energy flux at the pycnocline level of $2.5 \mathrm{~mW} \mathrm{~m}^{-2}$ (in the range [2$3.6] \mathrm{mW} \mathrm{m}^{-2}$ considering the full confidence interval) is of the order of $\sim 10 \%$ of the maximum of the wind power input at the mooring location (Figure 13b).

[64] Both approaches hence suggest that NIW contribute to an energy flux into the interior ocean which is of the order of $1 / 10$ of the power input at the surface, although the uncertainty on this number is quite large $(2-33 \%)$. We will compare this result with other studies in section 5.2.

\section{Estimates of Energy Dissipation and Eddy Diffusivity}

[65] In this section, we will try to assess the influence of the NIW groups on vertical mixing below the mixed layer. Figure 14 shows the evolution of the vertical shear modulus $S=\sqrt{\left(\frac{\Delta \mathrm{u}}{\Delta \mathrm{z}}\right)^{2}+\left(\frac{\Delta \mathrm{v}}{\Delta \mathrm{z}}\right)^{2}}$ and the inverse of Richardson number $R i^{-1}=S^{2} /_{N^{2}}$ at the mooring. The vertical structure of the shear associated with the first five baroclinic modes is also presented. The shear maxima occur in the thermocline around $70 \mathrm{~m}$ depth on 2 February and around $90 \mathrm{~m}$ depth on 9 February. The NIW ray tracing shows that these maxima clearly occur along the path of the NIW generated at the base of the mixed layer around 25 and 30 January. The maximum shear on 2 February is associated with the fifth baroclinic mode, whereas the secondary maximum on 9 February better fits with vertical modes 3 and 4. As already mentioned in section 3.2.3, the propagation time of the NIW is consistent with the separation time of the first five vertical modes. Similar results were found by Shay et al. [1989] who show that NIW-induced mixing associated with the passage of Hurricane Norbert in summer 1984 in the western equatorial Pacific results mainly from higher-order vertical modes (3 and 4).

[66] The inverse of the Richardson number expectedly displays large values in the mixed layer, frequently exceeding the critical value of 4 for which shear instabilities are expected. Below the mixed layer, critical values of $R i^{-1}$ occur at many isolated spots along the NIW path. When computed over a large $50 \mathrm{~m}$ scale $(\sim 1 / 2$ wavelength of the NIW in the thermocline) the Richardson number is always stable (not shown). This suggests that the NIW itself does not become unstable, but it is the superposition of the NIW velocity signal on the background shear that enhances intermittent breaking at small vertical scale $(10 \mathrm{~m}$ or less for which the $R i$ becomes locally unstable). The Gregg-Henyey parameterization [Gregg, 1989] is based on such an assumption. Estimates of kinetic energy dissipation rates $\varepsilon$ were therefore performed with this parameterization, which assumes a steady state GM spectrum of internal waves, where wavewave interactions transfer energy from large to small-scale motions. We used the form of the Gregg-Henyey scaling used in MacKinnon and Gregg [2005]:

$$
\varepsilon_{G H}=1.8 \cdot 10^{-6} f \cosh ^{-1}\left(N_{0} / f\right) \frac{N^{2}}{N_{0}^{2}} \frac{S_{10}{ }^{4}}{S_{G M}{ }^{4}}
$$

where $N_{0}=3 \mathrm{cph}$ is the reference GM value, $S_{G M}$ is the shear of the GM spectrum, $S_{G M}{ }^{4}=1.66 .10^{-10}\left(N^{2} / N_{0}^{2}\right)^{2}, N$ the in situ buoyancy frequency, and $S_{10}$ the shear computed for a vertical distance equal to $10 \mathrm{~m}$. Vertical eddy diffusivity is then computed using the Osborn [1980] relationship:

$$
K_{d}=\Gamma \frac{\varepsilon}{N^{2}}
$$

where $\Gamma=0.2$ is an upper bound for the mixing efficiency. Note that this parameterization is only applicable in the interior ocean (i.e., below the mixed layer) and that we focus on the impact of NIW on interior ocean mixing hereafter. Vertical profiles of averaged kinetic energy dissipation rates and eddy diffusivity inferred from mooring data are displayed in Figures 15a and b. The averaged profiles were computed over the pre-cyclone, cyclone, and post-cyclone periods. The impact of the storm is revealed by an increase of the dissipation rate down to the base of the pycnocline (typically within $50-100 \mathrm{~m}$ ) during the cyclone and postcyclone periods. The dissipation rate is twice as large during the post-cyclone period than during the precyclone period. These estimates show that the dissipation rate is increased during and after the storm, not only in the surface mixed layer (that never exceeds $60 \mathrm{~m}$ thickness) but also below, probably due to instability at small vertical scale promoted by enhanced shear along the internal wave path in the stratified ocean [Jaimes and Shay, 2010; Jaimes et al., 2011]. The impact of NIW is confined to the surface layer down to the pycnocline during the weeks following the storm. This is consistent with the analysis of internal wave generation showing a peak in energy flux around $90 \mathrm{~m}$ depth associated with near-inertial frequencies (Figures 11 and 12a).

[67] Values of dissipation rate vary within from $8 \times 10^{-10}$ $\mathrm{W} \mathrm{kg}^{-1}$ to $1 \times 10^{-7} \mathrm{~W} \mathrm{~kg}^{-1}$, i.e., significantly higher than the Garrett-Munk model in the first $100 \mathrm{~m}$. These results are consistent with previous estimates by Kunze et al. [2006] based on LADCP/CTD profiles. The depth-integrated dissipation rate in the pycnocline $(60-120 \mathrm{~m}$ depths) reaches values comparable to the maximum vertical energy flux (Figure 13) of $3 \mathrm{~mW} \mathrm{~m}^{-2}$. At depths below $100 \mathrm{~m}$ and down to $1000 \mathrm{~m}$ depth, there are no significant differences in dissipation between the pre- and post-storm periods (not shown). At those depths, the NIW packets that we have identified have been generated farther and earlier and may not be representative of Dora. Instead, they may be the result of the background high frequency wind fluctuations in that region due to, for example, convective mesoscale events. This would explain similarities at depth between the average dissipation profiles averaged during the pre- and postcyclone periods

[68] In order to estimate the contribution of near-inertial frequencies to the dissipation rate, we applied the fine-scale parameterization above to filtered shear (the near-inertial 

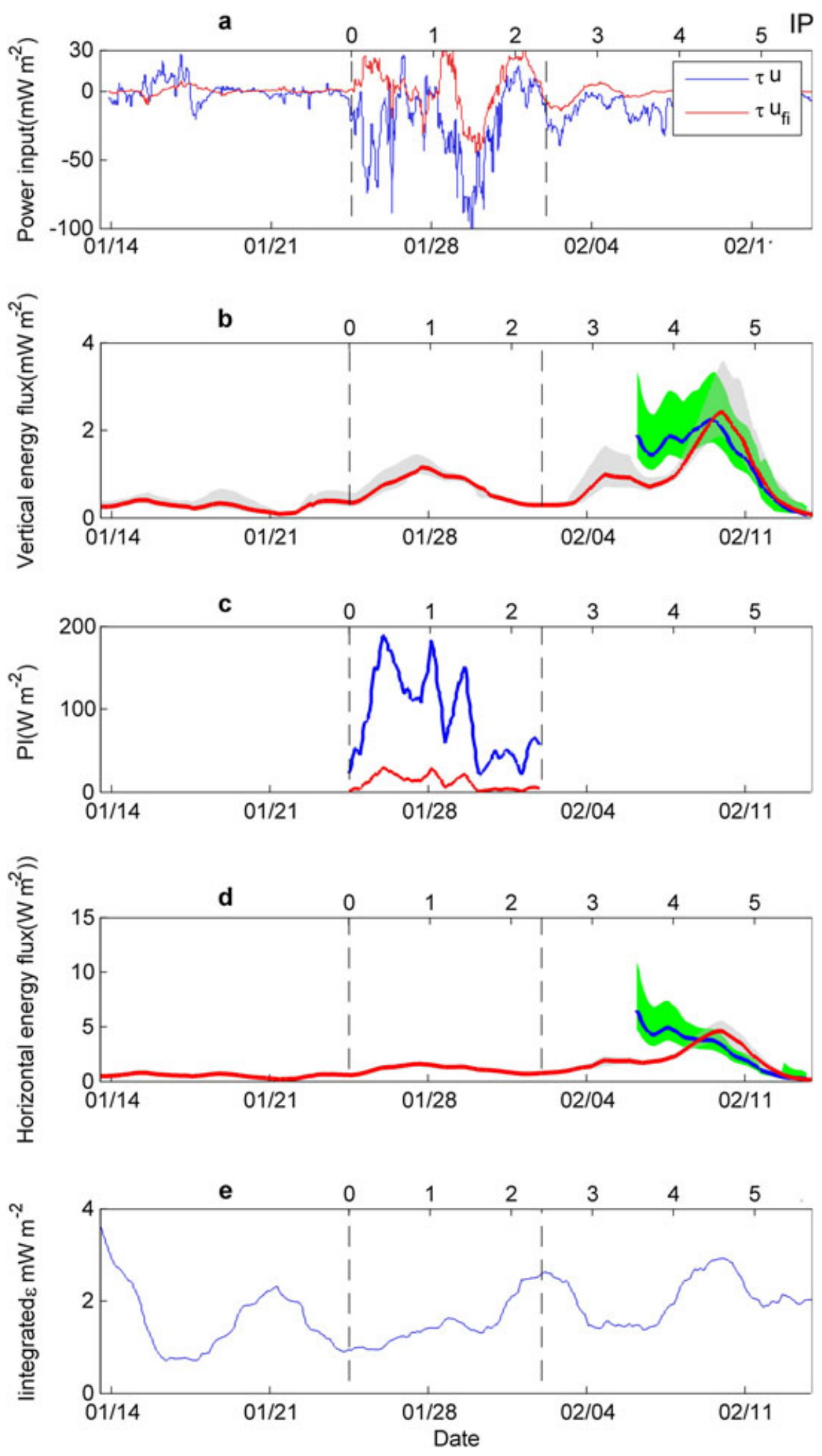

Figure 13. (a) Times series of wind work into total currents (blue) and inertial currents (red). (b) Maximum downward energy flux between the top $(60 \mathrm{~m})$ and base $(120 \mathrm{~m})$ of the pycnocline in blue for the FP station and in red for the mooring; shaded areas represent $95 \%$ confidence intervals. (c) Wind power input in blue for a fast-moving storm where $P_{i}=\frac{1}{2} \rho_{0} U_{h} u_{s}{ }^{2}$ and red for a slow-moving storm $\left(U_{h}<\right.$ $c_{1}$ ) where $P_{i}=\frac{1}{2} \rho_{0} u_{s}{ }^{3}$. (d) Horizontal energy flux in blue for the FP station and in red for the mooring; shaded areas represent the $95 \%$ confidence intervals. (f) Vertically integrated dissipation between 60 and $120 \mathrm{~m}$ depth. The time axis below each plot indicates the dates, while the time axis above the plots indicates the number of inertial periods after the first eyewall passage (e.g., after 24 January 2007). 
shear was subtracted from the total shear). The mean profile of this dissipation rate, $\varepsilon^{\prime}$, is compared to $\varepsilon$ in Figure $15 \mathrm{c} . \varepsilon^{\prime}$ and $\varepsilon$ differ by a factor of up to 8 , which reveals the very significant contribution of near-inertial internal waves to the dissipation rate in the top $140 \mathrm{~m}$.

[69] As the result of enhanced turbulence in the upper ocean, a significant increase in eddy diffusivity $K_{d}$ is observed down to the base of the pycnocline at about $80 \mathrm{~m}$ during the post-cyclone period, with values up to $2 \times 10^{-4} \mathrm{~m}^{2}$ $\mathrm{s}^{-1}$ at $\sim 50 \mathrm{~m}$ depth (Figure 15b). An important implication of turbulent mixing is the resulting heat transfer to the deep ocean. We computed diffusive heat fluxes $Q=K_{d} \partial_{z} T$ for the three periods (pre-, post-, and cyclone), with a vertical mixing coefficient including or not near-inertial frequencies (Figures 15d and 15e). As expected the diffusive heat flux is predominantly directed downward and increased during and after the storm (Figure 15a). The depth-average value of the heat flux within 40-140 m increased almost by a factor of 2 between the pre- and post-cyclone periods (with a mean value of $-8.7 \mathrm{~W} \mathrm{~m}^{-2}$ and $-15.1 \mathrm{~W} \mathrm{~m}^{-2}$, respectively). At the middle of the pycnocline, the increase in heating rate is even stronger with up to a threefold increase. The estimate of the contribution of NIW to the diffusive heat flux is striking: the depth-averaged heat flux is reduced by a factor of 10 when the near-inertial signal is not considered (Figure 15b).

[70] A more detailed view is provided in Figure 16a with a time-depth plot of the diffusive heat flux. $Q$ has typical negative values of $10-50 \mathrm{~W} \mathrm{~m}^{-2}$, corresponding to a downward diffusive transport of heat, with increased values during the cyclone and post-cyclone periods. Downward turbulent flux is first strong just beneath the mixed layer at the end of the pre-cyclone and during the cyclone period and then extends downward. Depths of maximum downward heat transport follow a similar pattern to that of increased shear along the NIW path (Figure 14a) and also match the depth of maximum shear for baroclinic modes 4 and 5, illustrating again the important role of NIW.

[71] Another way to estimate the impact of turbulent diffusion is to compute the local heating rate $\partial_{z}\left(K_{d} \partial_{z} T\right)$ (Figure 16b). Depths of increased local heating and cooling appear along the trajectory of the internal gravity wave packet excited locally at the mooring during the storm. Fairly large values are observed, with up to $10^{\circ} \mathrm{C} \mathrm{month}^{-1}$
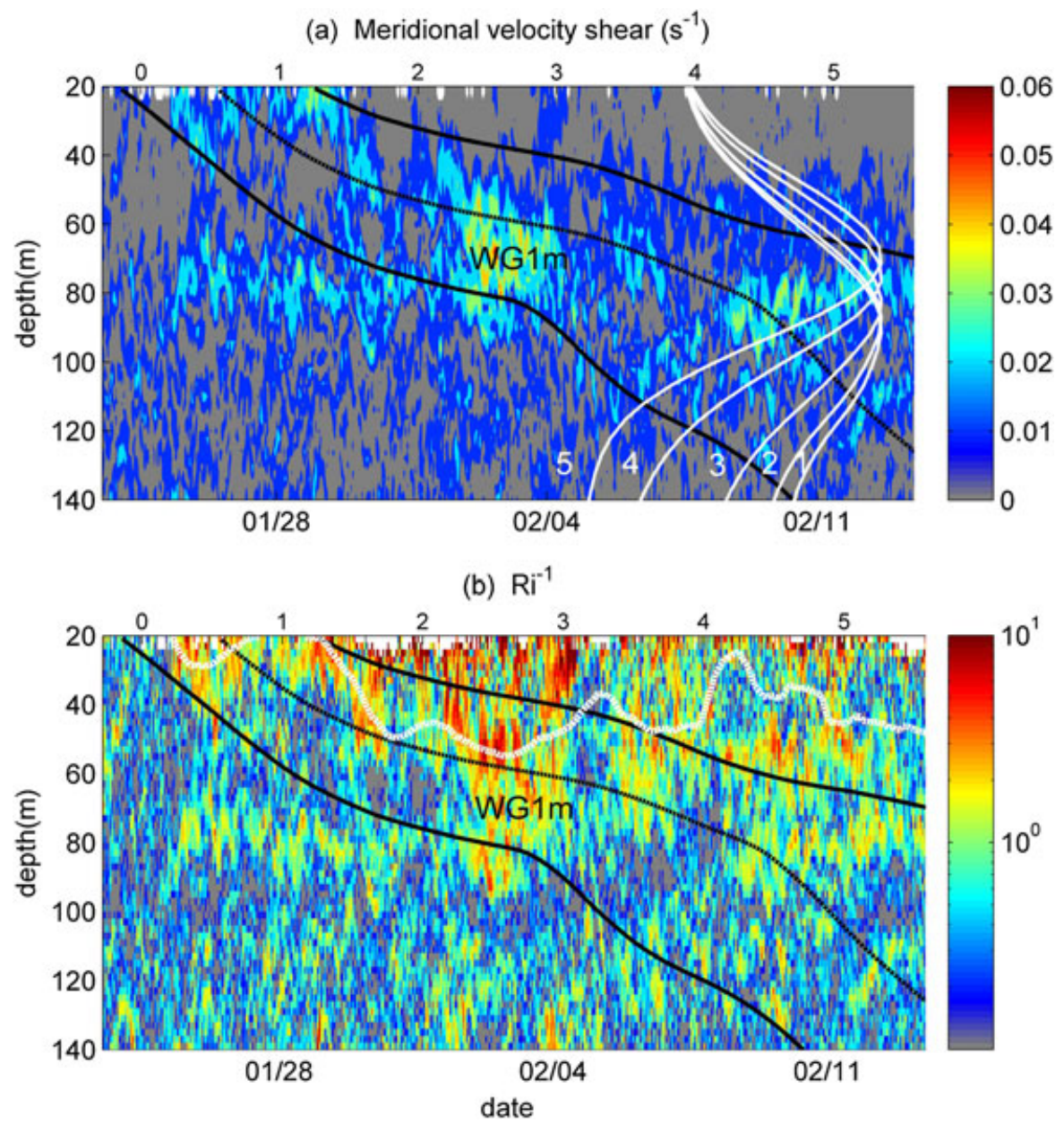

Figure 14. (a) Vertical shear of the velocity modulus (computed at $4 \mathrm{~m}$ vertical resolution). The black lines show NIW rays trajectories computed from the vertical group velocity (see text for details). The white lines represent the vertical structure of the shear associated with the first five baroclinic modes $\left(d P_{n} / d z\right)$. (b) Inverse of the Richardson number. The white dashed line indicates the mixed layer depth. 
a). Mean profiles of $\varepsilon$

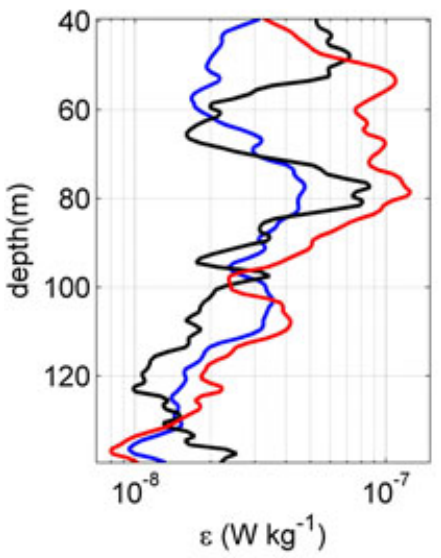

b). Mean profiles of $\mathrm{K}_{d}$

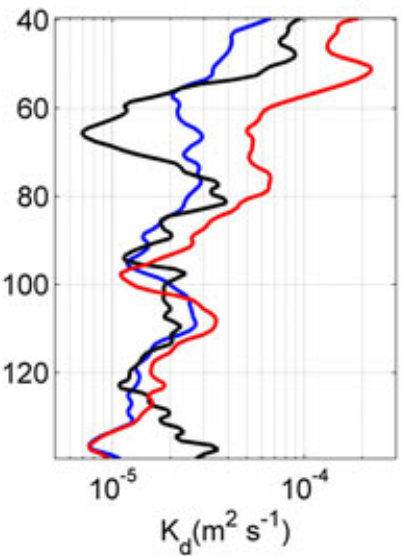

c). Mean profiles of $\varepsilon$

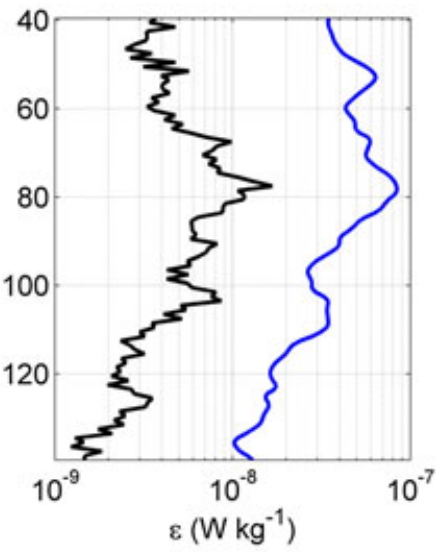

d). Mean profiles of diffusive heat flux

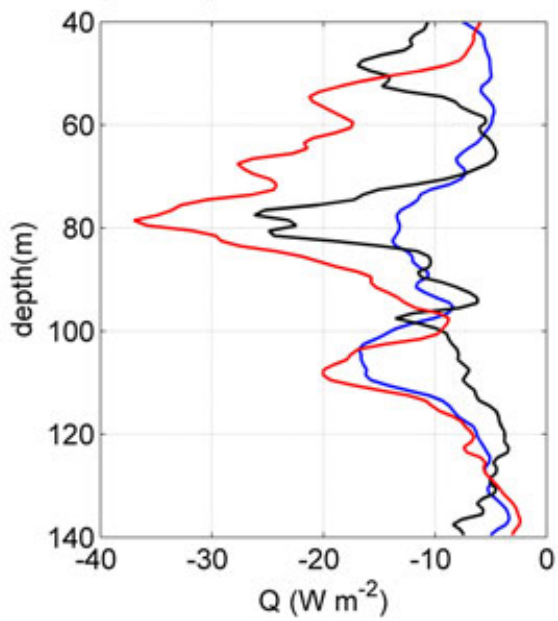

e). Mean profiles of diffusive heat flux

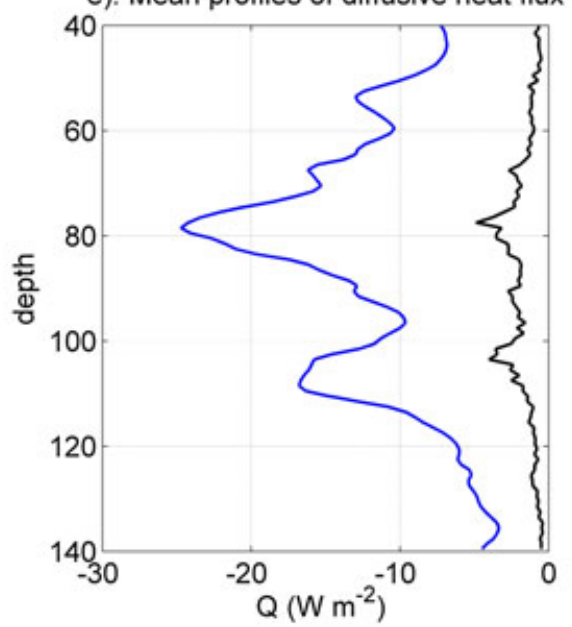

Figure 15. Estimates of dissipation rate and eddy diffusivity at the ATLAS mooring inferred from shear using mooring data: (a) dissipation rates $\varepsilon$ averaged over leg 1 (in blue), inter-leg (in black) period, and leg 2 (in red); (b) same as Figure 15a but for eddy diffusivity, Kd; and (c) mean profile of $\varepsilon$ averaged over the entire period: $\varepsilon$ inferred from total shear is displayed in dark blue, whereas $\varepsilon$ inferred from total shear minus inertial shear in black. Vertical heat flux at the ATLAS mooring: (d) profile of vertical diffusive heat flux time averaged over leg 1 (blue), inter-leg period (black), and leg 2 (red); (e) profile of vertical diffusive heat flux time averaged over leg 2 with (blue) and without (black) the contribution of near-inertial currents to the vertical turbulent diffusivity.

locally and a dominance of heating over cooling after the onset of the storm (note that, in comparison, the effect of penetrative solar heat flux is about $\sim 0.5^{\circ} \mathrm{Cmonth}^{-1}$ at $40 \mathrm{~m}$ and decreases exponentially below). We also averaged the heating rate between different isopycnals in order to provide a more quantitative assessment of the role of mixing (Figure 16 and Table 2). Three intervals have been chosen that correspond respectively to the layer just below the mixed layer $\left(22-23 \mathrm{~kg} \mathrm{~m}^{-3}\right.$, layer L1), within the thermocline/pycnocline $\left(23-24 \mathrm{~kg} \mathrm{~m}^{-3}\right.$, layer L2), and below the thermocline/pycnocline (24-25 $\mathrm{kg} \mathrm{m}^{-3}$, layer L3). The temporal evolution for each isopycnal-averaged heating rate is displayed in Figure 16c. The general opposition between the heating rate for L1 (mostly cooling) and L2/L3 (mostly heating) illustrates clearly the downward transport of heat by mixing (heat is removed from below the mixed layer to warm deeper levels). Except for a mixing event during the pre-cyclone period, the frequency of surface cooling/ subsurface heating events increases as time goes on, with most events occurring during the post-cyclone period. Heating events also occur later within L3 than within L2, which is consistent with NIW downward propagation. The average heating rate for $\mathrm{L} 3$ increases from $0.03^{\circ} \mathrm{C}$ month $^{-1}$ during the cyclone period and up to $0.27^{\circ} \mathrm{C} \mathrm{month}^{-1}$ during the post-cyclone period. In contrast, the average heating rate of about $0.4^{\circ} \mathrm{Cmonth}^{-1}$ within $\mathrm{L} 2$ is almost unchanged during the cyclone and post-cyclone periods. The average values in Table 2 also allows for quantification of the increase in heating by vertical mixing associated with NIW. During the pre-cyclone period (characterized by little or no NIW activity), the average heating rate due to mixing is $\sim 0.06^{\circ} \mathrm{Cmonth}^{-1}$ in the thermocline and $0.08^{\circ} \mathrm{C}$ month ${ }^{-1}$ below. During the post-cyclone period characterized by strong NIW in the thermocline and below, those heating rates increase to $0.42{ }^{\circ} \mathrm{C}$ month $^{-1}$ and $0.27^{\circ} \mathrm{C}$ month $^{-1}$, respectively. 


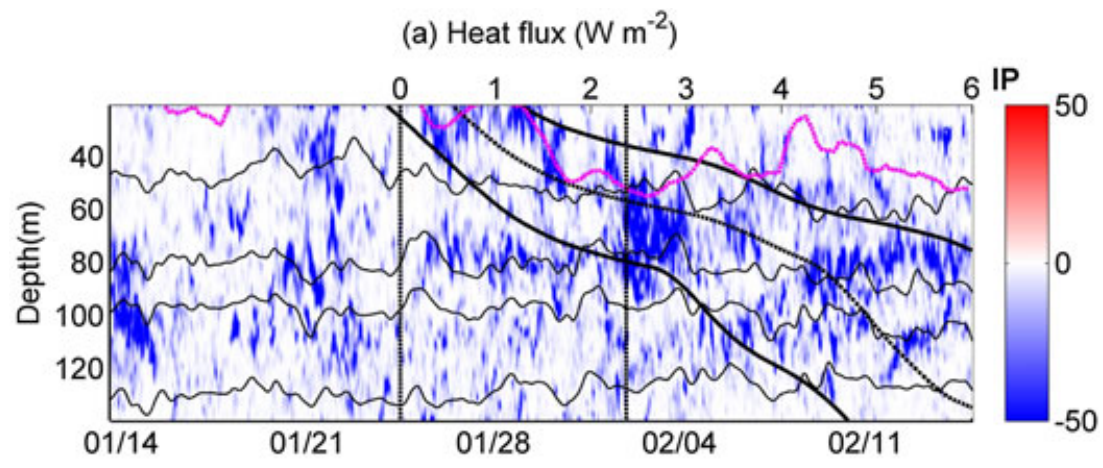

(b) Heating rate $\left({ }^{\circ} \mathrm{C}\right.$ month $\left.{ }^{-1}\right)$
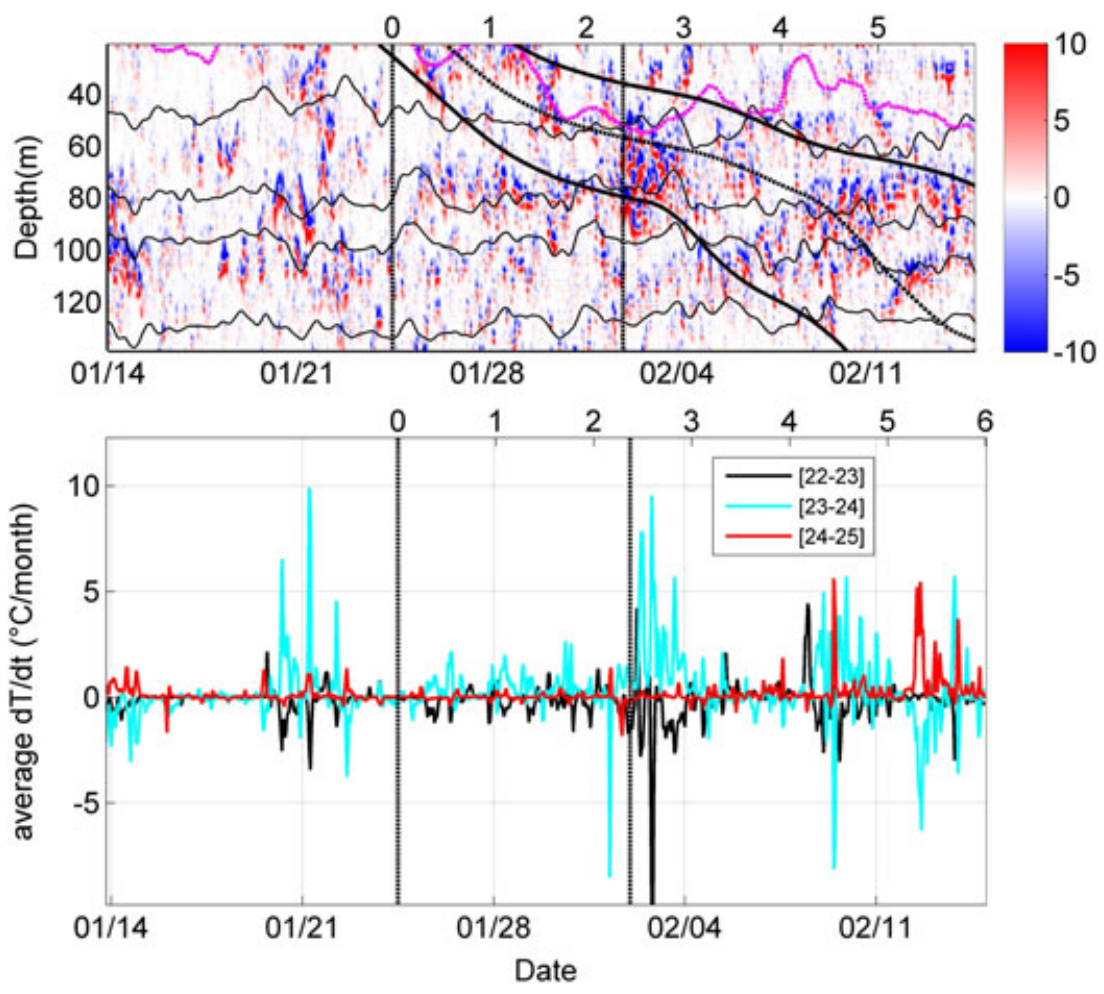

Figure 16. (a) Time depth plot of vertical diffusive heat flux at the ATLAS mooring; (b) same as Figure 16a for the heating rate; for each plot, black lines represent isopycnal contours [22-25] $\mathrm{kg} \mathrm{m}^{-3}$; thick black plain and dashed lines represent near-inertial waves ray characteristics for WG1m and magenta dashed line represents the mixed layer depth. (c) Temporal evolution of the heating rate at $\mathrm{M}$ averaged between isopycnals $[22,23],[23,24]$, and $[24,25] \mathrm{kg} \mathrm{m}^{-3}$.

\section{Summary and Discussion}

\subsection{Summary}

[72] The Cirene cruise provides a 1 month long record of air-sea interface and subsurface high frequency observations in the southwestern tropical ocean in early 2007. During the cruise, a tropical storm formed almost exactly at the location of a ship station and ATLAS mooring deployed during the cruise $\left(8^{\circ} \mathrm{S}, 67^{\circ} \mathrm{E}\right)$ and later developed into tropical cyclone Dora. This provides an opportunity to describe the upper ocean response to strong atmospheric forcing and generation of NIW at this climatically relevant site of the Indian Ocean [Xie et al., 2002; Vialard et al., 2009]. Weak winds ( $<5 \mathrm{~m}$ $\left.\mathrm{s}^{-1}\right)$, shallow mixed layers $(\sim 20 \mathrm{~m})$ and intense downward solar radiation characteristic of a break phase of the Madden-
Julian oscillation preceded the cruise. This was followed by a period of strong winds $\left(\sim 10 \mathrm{~m} \mathrm{~s}^{-1}\right.$ and wind stresses of $\sim 0.2 \mathrm{~N}$ $\mathrm{m}^{-2}$, i.e., characteristic values for a tropical depression) and $\sim 300 \mathrm{~mm}$ of cumulated rainfall as the storm formed and traveled southward over the cruise site (25 January to 2 February 2007). Weaker winds then progressively returned as Dora intensified but moved away. The oceanic response was characterized by a $\sim 2^{\circ} \mathrm{C}$ cooling of the sea surface and a suppressed the diurnal cycle.

[73] In response to the storm, a clear NIW response was seen in the velocity field within the oceanic mixed layer for about 1 week after the passage of the storm. Inertial pumping in the mixed layer drove NIW that propagated vertically into the interior ocean, as illustrated by clear upward phase propagation in the velocity field. Phase 
analysis of the upward-propagating part of the velocity field identifies five wave packets in the data. The first wave group (WG1) had current variations of $\sim 0.25 \mathrm{~m} \mathrm{~s}^{-1}$ within and below the pycnocline $(100-200 \mathrm{~m})$. The deepest wave packet had an amplitude of $\sim 0.15 \mathrm{~m} \mathrm{~s}^{-1}$ and propagates below $1000 \mathrm{~m}$, the maximum depth of the measurements.

[74] We then identified the main characteristics of each wave packet (e.g., horizontal and vertical wave numbers, and intrinsic frequency), largely based on the method proposed by Alford and Gregg [2001]. The first two wave groups (identified in the upper $400 \mathrm{~m}$ ) had rather large horizontal scales ( 200-300 km), comparable to horizontal scales in the forcing before the eye formation, and appeared to propagate northward. The deeper-identified wave groups (500-1000 m) appeared to have smaller horizontal scales $(\sim 80 \mathrm{~km})$, and some of them displayed apparent southward propagation. All wave packets carried energy downward: $\sim 2 \mathrm{~mW} \mathrm{~m}^{-2}$ down to $400 \mathrm{~m}$ for WG1 and WG2 and $\sim 1 \mathrm{~mW}$ $\mathrm{m}^{-2}$ down to $1000 \mathrm{~m}$ for WG3-WG5. While it is difficult to compare this vertical energy flux to the wind power input from measurements at a single location, it is interesting to note that the maximum vertical energy flux at thermocline level (between 60 and $120 \mathrm{~m}$ ) corresponds to about $10 \%$ of the maximum surface wind power input, implying that a non-negligible fraction of the energy input of this developing storm penetrated below the thermocline.

[75] Finally, we diagnosed the potential influence of those NIW on mixing in the interior ocean (i.e., below the mixed layer). There was twofold increase of the kinetic energy dissipation rate in the interior ocean between the pre-cyclone period (with little internal wave propagation in the interior ocean) and post-cyclone period. A simple vertical mixing parameterization identified a downward vertical mixing heat flux within the thermocline of $\sim 10 \mathrm{~W} \mathrm{~m}^{-2}$ during the pre-cyclone period versus approximately $-25 \mathrm{~W} \mathrm{~m}^{-2}$ during the cyclone period and $-35 \mathrm{~W} \mathrm{~m}^{-2}$ during the post-cyclone period (which was also the main period of internal wave activity). The associated heat flux convergence resulted in average mixing-induced heating rates within the thermocline of $\sim 0.42{ }^{\circ} \mathrm{C} \mathrm{month}^{-1}$ during the post-cyclone period versus only $0.06{ }^{\circ} \mathrm{Cmonth}^{-1}$ during the pre-cyclone period. This suggests a strong increase of vertical mixing in the thermocline associated with the increase of vertical shear along the paths of downward-propagating internal wave energy.

\subsection{Discussion}

[76] The vertical NIW energy flux $\left(\sim 2.5 \mathrm{~mW} \mathrm{~m}^{-2}\right)$ induced by Dora is comparable to other estimates of baroclinic NIW energy fluxes generated by moderate to strong wind events. Qi et al. [1995] estimated 2-6 $\mathrm{mW} \mathrm{m}^{-2}$ of downward NIW energy fluxes as the result of storms in the Northeast Pacific $\left(47^{\circ} \mathrm{N}\right)$ Ocean. At a latitude of $6.5^{\circ} \mathrm{S}$ comparable to Cirene ( $\left.8^{\circ} \mathrm{S}\right)$, Alford and Gregg [2001] estimated NIW baroclinic downward energy flux of $2 \mathrm{~mW} \mathrm{~m}^{-2}$ as the result of strong monsoon winds in the Banda Sea. However, energy fluxes associated with a fully developed hurricane can be much larger. For instance Jaimes and Shay [2010] found a downward NIW energy flux of $79 \mathrm{~mW} \mathrm{~m}^{-2}$ and an upward energy flux of $254 \mathrm{~mW} \mathrm{~m}^{-2}$ associated with Hurricane Katrina. In their case, energy fluxes corresponded to a category 5, fast moving hurricane and were estimated for conditions inside geostrophic vortices that often are found to enhance vertical near-inertial wave propagation. Although they did not estimate vertical energy fluxes, Sanford et al. [2007] found near-inertial horizontal velocities reaching $\pm 1.5 \mathrm{~m} \mathrm{~s}^{-1}$ just after the passage of Hurricane Frances.

[77] In this paper, we distinguish three different NIW groups (WG3-WG5) at depth $(z>500 \mathrm{~m})$ at the mooring location. These wave groups show significant near-inertial current amplitude (up to $30 \mathrm{~cm} \mathrm{~s}^{-1}$ ) and vertical energy fluxes of up to $1 \mathrm{~mW} \mathrm{~m}^{-2}$ (Figures 8 and 11), which suggest that their energy efficiently propagated downward from the surface. They were however not related to Dora or any other tropical storm or cyclone in the region. They are moreover characterized by relatively short horizontal wavelengths. This may be due to the very fine scale of the background atmospheric forcing in this region, where mesoscale convective variability can induce wind variations on spatial scales of a few kilometers to a few tens of kilometers. In addition, WG3 propagates poleward whereas equatorward propagation is expected from the $\beta$ effect dispersion [Garrett, 2001]. The background vorticity field may however have influenced the propagation of these wave groups. Background vorticity $\zeta$ indeed shifts the inertial frequency to an effective inertial frequency $f_{\text {eff }}=f+1 / 2 \zeta$. Such modification of $f_{\text {eff }}$ can be much larger than the variation of $f$ on the $\beta$ plane and explain poleward propagation. At midlatitudes, where eddy variability is often strong, observations show a strong impact of mesoscale vorticity on NIW propagation [Kunze, 1995; Jaimes and Shay, 2010]. Mesoscale activity at the low latitude Cirene location $\left(8^{\circ} \mathrm{S}\right)$ is however much weaker, but the deep, westward jet generated by the Indian Ocean Dipole [Vialard et al., 2009] may have produced such modifications of the background vorticity. Figure 17 shows a very rough proxy of this vorticity from the meridional shear $\left(-\frac{\partial u}{\partial y}\right)$ of the surface zonal velocity $u$ recorded by the ship ADCP along a meridional transect at $67^{\circ} \mathrm{E}$ between 1 and 14 January and smoothed using a running mean of $40 \mathrm{~km}$. The order of magnitude of $f_{\text {eff }}$ variations at the surface obtained from this estimate (Figure 17) is larger than the equatorward inertial frequency decrease from the $\beta$ effect

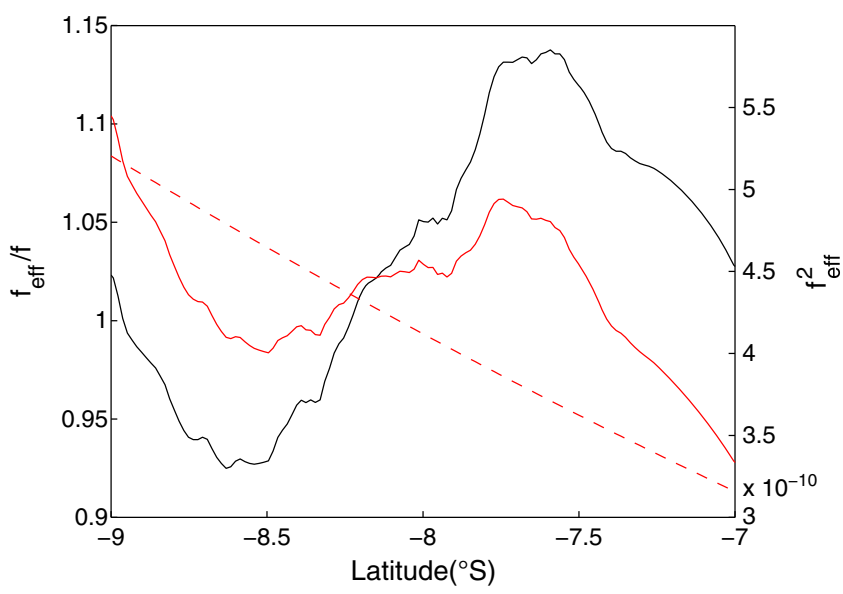

Figure 17. Ratio of surface effective inertial frequency $f_{\text {eff }}$ and inertial frequency $f$ along a $67^{\circ} \mathrm{E}$ transect, estimated from the ship ADCP zonal velocity shear in black line. Red line is squared surface effective inertial frequency $f_{\text {eff }}^{2}$ and red dashed line is $f^{2}$. 
at the ATLAS mooring and FP station (red curve). Near $8^{\circ} \mathrm{S}$, $f_{\text {eff }}$ has a local maximum, which may allow southward propagation in addition to the more classical equatorward propagation. Note that the wave will conserve its intrinsic frequency while propagating at depth and will be able to propagate poleward until its intrinsic frequency equals the local effective frequency. Clearly the effective frequency at the surface and at depth can be different, and an accurate computation of the generation point and turning point location for each wave group would require knowledge of the 3-D mesoscale field. We leave a quantitative computation of ray path in space and time for future modeling studies.

[78] This paper suggests that a non-negligible part ( 10\%) of the energy injected into inertial currents by the storm may propagate below the mixed layer under the form of NIW. This energy escapes the mixed layer to be dissipated within the pycnocline and in the deep ocean. The passage of the NIW triggered by Dora for example induces significant mixing and heating rates in the pycnocline. Generation of NIW hence appears as an efficient mechanism to redistribute momentum and induce mixing below the mixed layer. As a consequence, fast propagation of NIW at depth can reduce storm-induced mixing in the surface layer and hence the surface cooling, as shown by Jaimes and Shay [2010] after Hurricanes Katrina and Rita. We can therefore expect a climatic impact of NIWs, notably in regions of strong ocean atmosphere interactions as the Cirene region [e.g., Xie et al., 2002; Vialard et al., 2009]. The very local nature of the measurements collected during the cruise does not allow us to investigate in detail the influence of the associated mixing on the ocean thermal structure, nor the fate of the energy that is injected in the deep ocean. Furthermore, while Cirene measurements are interesting because of the intense air-sea coupling in this region, the location where maximum cyclone intensity (and energy transfer to the ocean) occurred was further south.

[79] A good representation of NIW generation, propagation, and dissipation is needed in Ocean General Circulation Models (OGCMs) in order to characterize the climatic impact of NIW energy. Although horizontal resolution of state-of-the-art OGCMs is generally sufficient to represent cyclones and storms-induced NIWs, two difficulties arise. First, atmospheric forcing at very fine scale (e.g., the very strong winds within the cyclone eyewall) is not resolved by current re-analysis products, which are used to force the OGCMs (horizontal resolution of $10 \mathrm{~km}$ is probably necessary to resolve the basic eye and eyewall structure in the atmospheric forcing, Halliwell et al., 2011). Second, the use of current parameterizations of dissipation such as the turbulent kinetic energy (TKE)-based parameterization [Mellor and Yamada, 1982] and the use of geopotential coordinates [Levaillant, 2009] result in an artificial damping of internal waves. Leclair and Madec [2011] recently proposed new vertical coordinates that reduce the artificial damping on NIWs and may result in a better representation of internal waves in high resolution OGCMs. A more physically relevant parameterization of internal wave-induced dissipation may then be implemented from the most recent formulations [Gregg, 1989; Kunze, 2006]. Vincent et al. [2011a, 2011b] have developed an interesting framework to include tropical cyclone wind forcing in a general circulation model. We aim at using this framework in a relatively high resolution $\left(1 / 4^{\circ}\right)$ model of the Indian Ocean, in order to study the effect of NIW at large spatial scales and seasonal time scales.

[80] Finally, we also observed clear energy peaks at the diurnal and semidiurnal time scale, associated to internal tides. Internal tides are indeed expected in this region, where a mid-ocean ridge (see Figure $1 \mathrm{~b}$ ) is associated with rugged bottom topography. The stronger mixing in the pycnocline observed during post-cyclone period is clearly associated with NIW, but as opposed to the sporadic forcing of NIW by tropical depressions or cyclones, tidal forcing is ever present and internal tidal mixing is probably important for the longer term heat budget. We will discuss and pursue this topic in a separate paper on the basis of these observations and a simple linear internal tide model (Cuypers et al., manuscript in preparation, 2013).

[81] Acknowledgments. We thank Claudie Marec from INSU and Jacques Grelet from IRD for their technical support in the deployment of the mooring, collection of the CTD/LADCP profiles, and the processing of the data. B. Luong implemented the Schütze and Schwetlick free-knot spline algorithm that we use to isolate wave groups. JV is funded by Institut de Recherche pour le Développement (IRD). MJM is funded by NOAA. The LEFE/IDAO program of the CNRS (Centre National de la Recherche Scientifique) also supported this work. This is PMEL Contribution 3804.

\section{References}

Alford, M. H. (2001), Internal swell generation: The spatial distribution of energy flux from the wind to mixed layer near-inertial motions, J. Phys. Oceanogr., 31, 2359-2368.

Alford, M. H., (2003), Improved global maps and 54-year history of windwork on ocean inertial motions, Geophys. Res. Lett., 30, 1424. doi:10.1029/2003GL018543.

Alford, M. H., and M. C. Gregg (2001), Near-inertial mixing: Modulation of shear, strain and microstructure at low latitude, J. Geophys. Res., 106, C8, $16,947-16,968$.

Bentamy, A., K. B. Katsaros, M. Alberto, W. M. Drennan, and E. B. Forde (2002), Daily surface wind fields produced by merged satellite data. Amer. Geophys. Union, Geophys. Monogr. Ser., 127, 343-349.

Bonjean, F., and G. S. E. Lagerloef (2002), Diagnostic model and analysis of the surface currents in the tropical Pacific Ocean. J. Phys. Oceanogr., 32, 2938-2954.

Bouruet-Aubertot, P., H. Mercier, F. Gaillard, and P. Lherminier (2005), Evidence of strong inertia gravity wave activity during the POMME experiment. J. Geophys. Res., 110, doi:10.1029/2004JC002747, 2005.

Broecker, W. S. (1991), The great ocean conveyor. Oceanography, 4, 79-89.

Cairns, J. L. and G. Williams (1976), Internal waves observation from a mid water float, J. Geophys. Res., 81: 1943-1950.

Chang, S. and R. Anthes (1978), Numerical simulations of the ocean's nonlinear baroclinic response to translating hurricanes. J. Phys. Oceanogr., 8, 468-480.

Fairall, C. W., E. F. Bradley, J. E. Hare, A. A. Grachev, and J. B. Edson, (2003), Bulk parameterization of air-sea fluxes: Updates and verification for the COARE algorithm. J. Climate, 16, 571-591.

Fofonoff, N. P., (1969), Spectral characteristics of internal waves in the ocean, Deep Sea Res., 16, (Suppl.), 59-71.

Foltz, G. R., J. Vialard, B. Praveen Kumar and M. J. McPhaden (2010), Seasonal mixed layer heat balance of the southwestern tropical Indian Ocean, J. Clim., 23, 947-965.

Furuichi, N., T. Hibiya, and Niwa Y. (2008), Model-predicted distribution of wind-induced internal wave energy in the world's oceans. J. Geophys. Res. 113, C09034. doi:10.1029/2008JC004768.

Garrett, C. (2001), What is the "near-inertial" band and why is it different from the rest of the internal wave spectrum? J. Phys. Oceanogr., 31, 962-971.

Geisler, J. E. (1970), Linear theory on the response of a two layer ocean to a moving hurricane. Geophys. Fluid Dyn., 1, 249-272.

Gerkema T. and J. T. F Zimmerman (2008), Lecture notes Royal NIOZ, Texel.

Gill, A. E. (1982), Atmosphere-Ocean Dynamics, Academic Press, 662 pp. Gill, A. E. (1984), On the behavior of internal waves in the wake of storms. J. Phys. Oceanogr., 14, 1129-1151. 


\section{CUYPERS ET AL.: STORM-INDUCED NIW DURING CIRENE}

Gregg, M. C., (1989), Scaling turbulent dissipation in the thermocline. J. Geophys. Res., 94, 9686-9698.

Halliwell, G., Shay L. K., J. K. Brewster, and W. J. Teague (2011), Evaluation and sensitivity analysis to an ocean model to Hurricane Ivan. Mon. Wea. Rev., 139, 921-945.

Hebert, D., and J. N. Moum (1994), Decay of near inertial wave. J. Phys. Oceanogr., 24, 2334-2351.

Jaimes, B. and L. K. Shay (2009), Mixed layer cooling in mesoscale oceanic eddies during Hurricanes Katrina and Rita. Mon. Wea. Rev., $137,4188-4207$.

Jaimes, B. and L. K. Shay (2010), Near-inertial wave wake of Hurricanes Katrina and Rita over mesoscale oceanic eddies. J. Phys. Oceanogr., 40, 1320-1337.

Jaimes, B., Shay L. K., and G. R. Halliwell (2011), The response of quasi geostrophic oceanic vortices to tropical cyclone forcing. J. Phys. Oceanogr., 41, 1965-1985.

Jayakumar, A., J. Vialard, M. Lengaigne, C. Gnanseelan, J. P. McCreary and B. Praveen Kumar (2011), Processes controlling the surface temperature signature of the Madden-Julian oscillation in the thermocline ridge of the Indian Ocean, Clim. Dyn., 37, 2217-2234.

Knapp, K. R., M. C. Kruk, D. H. Levinson, H. J. Diamond, and C. J. Neumann (2010), The International Best Track Archive for Climate Stewardship (IBTrACS). Bull. Amer. Meteor. Soc. 91, 363-376.

Koch-Larrouy A., M. Lengaigne, S. Masson, G. Madec, P. Terray (2008), Tidal mixing in the Indonesian Seas and its effect on the tropical climate system. Clim. Dyn. 34(6): 891-904, doi:10.1007/s00382-009-0642-4.

Kunze, E., (1985), Near-inertial wave propagation in geostrophic shear. $J$. Phys. Oceanogr., 15, 544-565.

Kunze, E., (1995), The energy balance in a warm-core ring's near-inertial critical layer. J. Phys. Oceanogr., 25, 942-957.

Kunze, E., E. Firing, J. M. Hummon, T. K. Chereskin, and A. M. Thurnherr (2006), Global abyssal mixing inferred from lowered ADCP shear and CTD strain profiles. J. Phys. Oceanogr., 36, 1553-1576.

Leaman, K. D. (1976), Observations of vertical polarization and energy flux of near-inertial waves. J. Phys. Oceanogr., 6, 894-908.

Leclair, M., and G. Madec (2011), $\widetilde{Z}$-coordinate, an arbitrary LagrangianEulerian coordinate separating high and low frequency motions. Ocean Modelling 37(3-4): 139-152.

Levaillant, X. (2009), Ondes internes générées par le forçage atmosphérique dans l'océan Indien subtropical: modélisation et mesures in situ. Thesis Université Paris 6.

Lloyd, I. D. and G. A. Vecchi (2010), Submonthly Indian ocean cooling events and their interaction with large-scale conditions. J. Climate, 23, $700-716$.

Locarnini, R. A., A. V. Mishonov, J. I. Antonov, T. P. Boyer, H. E. Garcia, O. K. Baranova, M. M. Zweng, and D. R. Johnson (2010), World Ocean Atlas 2009, Volume 1: Temperature, edited by S. Levitus, pp. 184, NOAA ATLAS NESDIS 68, U.S. Government Printing Office, Washington, D.C.

MacKinnon, J. A. and M. C. Gregg (2005), Spring mixing: Turbulence and internal waves during restratification on the New England Shelf. $J$. Geophys. Res., 35, 2425-2443.

Marotzke, J., and J. R. Scott (1999), Convective mixing and the thermohaline circulation. J. Phys. Oceanogr., 29, 2962-2970.

Mellor, G. L. and T. Yamada (1982), Development of a turbulence closure model for geophysical fluid problems. Rev. Geophys., 20, 851-875.

McCreary, J. P., P. K. Kundu and R. L. Molinari (1993), A numerical investigation of dynamics, thermodynamics and mixed-layer processes in the Indian Ocean, Prog. Oceanogr., 31, 181-244.

McPhaden, M. J., G. Meyers, K. Ando, Y. Masumoto, V. S. N. Murty, M. Ravichandran, F. Syamsudin, J. Vialard, L. Yu, and W. Yu (2009), RAMA: The research moored array for African-Asian-Australian monsoon analysis and prediction. Bull. Am. Meteorol. Soc., 90, 459-480.

Munk, W., and Wunsch, C. (1998), Abyssal recipes II: Energetics of tidal and wind mixing. Deep-Sea Res. I, 45, 1977-2010.

O'Brien, J. J., and R. O. Reid (1967), The non-linear response of a two-layer, baroclinic ocean to a stationary, axially-symmetric hurricane: Part I. Upwelling induced by momentum transfer. J. Atmos. Sci., 24, 197-207.

Osborn, T. R. (1980), Estimates of the local rate of vertical diffusion from dissipation measurements. J. Phys. Oceanogr., 10, 83-89.
Park, T. W, and C. S. Burrus (1987), Digital filter design. John Wiley \& sons.

Perkins, H. (1970), Inertial oscillations in the Mediterranean, Ph D. thesis. Massachusetts Institute of Technology, Woods Hole, $155 \mathrm{pp}$.

Pollard, R. T. (1970), On the generation by winds of inertial waves in the ocean. Deep Sea Res., 17, 795-812.

Price, J. F. (1981), Upper ocean response to a hurricane. J. Phys. Oceanogr., 11, 153-175.

Qi, H., R. A. De Szoeke, C. A. Paulson, and C. C. Eriksen (1995), The structure of near-inertial waves during ocean storms. J. Phys. Oceanogr., 25, 2853-2871.

Saji, N. H., B. N. Goswami, P. N. Vinayachandran and T. Yamagata (1999), A dipole mode in the tropical Indian Ocean. Nature, 401, 360-363.

Sanford, T. B., Price J. F., Girton, J. B. and Webb D. C. (2007), Highly resolved observations and simulations of the ocean response to a hurricane. Geophys. Res. Lett. 34, L13604.

Schott, F. A., S.-P. Xie, and J. P. McCreary Jr. (2009), Indian Ocean circulation and climate variability, Rev. Geophys., 47, doi:10.1029/ 2007RG000245.

Shay, L. K., R. L. Elsberry, and P. G. Black (1989), Vertical structure of the ocean current response to a hurricane. J. Phys. Oceanogr., 19, 1249-1269.

Shütze, T. and Schwetlick (1997), Constrained approximations by splines with freeknots. BIT, 37:1, 105-137.

Smith, W. H. F. and D. Sandwell (1997), Global sea floor topography from satellite altimetry and ship depth soundings. Science, 26, 277(5334): 1956-1962.

Sriver, R. L. and M. Huber (2007), Observational evidence for an ocean heat pump induced by tropical cyclones, Nature, 447, 577-580.

Torrence, C. and G. P. Compo (1998), A practical guide to wavelet analysis, Bull. Am. Meteorol. Soc., 79, 61-78.

Vialard, J., G. Foltz, M. J. McPhaden, J. P. Duvel and C. de Boyer Montégut (2008), Strong Indian Ocean sea surface temperature signals associated with the Madden-Julian oscillation in late 2007 and early 2008. Geophys. Res. Lett., 35, L19608, doi:10.1029/2008GL035238.

Vialard, J., et al., (2009), Cirene: Air-sea interactions in the seychelles-chagos thermocline ridge region. Bull. Am. Meteor. Soc. 90(1), 45-61.

Vinayachandran, P. N., J. Kurian, and C. P. Neema, (2007), Indian Ocean response to anomalous conditions in 2006. Geophys. Res. Lett., 34, L15602, doi:10.1029/2007GL030194.

Vincent, E., M. M. Lengaigne, G. Madec, J. Vialard, G. Samson, N. Jourdain, C. E. Menkes and S. Jullien (2012a), Processes setting the characteristics of sea surface cooling induced by tropical cyclones, $J$. Geophys. Res., 117, C02020, doi:10.1029/2011JC007396.

Vincent, E., M. M. Lengaigne, J. Vialard, G. Madec, N. Jourdain, and S. Masson (2012b), Assessing the oceanic control on the amplitude of sea surface cooling induced by tropical cyclones, J. Geophys. Res., 117, doi:10.1029/2011JC007705.

Von Storch J. S., H. Sasaki, and J. Marotzke (2007), Wind-generated power input to the deep ocean: an estimate using a $1 / 10^{\circ}$ general circulation model. J. Phys. Oceanogr. 37, 657-672.

Watanabe, M. and T. Hibiya (2002), Global estimates of the wind-induced energy flux to inertial motions in the surface mixed layer, J. Geophys. Res., 29, 1239-1247.

Webster, P. J., A. M. Moore, J. P. Loschnigg, and R. R. Leben (1999), Coupled oceanic atmospheric dynamics in the Indian Ocean during 1997-98, Nature, 401, 356-360.

Wunsch, C. (1998), The work done by the wind on the ocean general circulation model. J. Phys. Oceanogr., 28, 2332-2340.

Wunsch, C., and R. Ferrari (2004), Vertical mixing, energy and the general circulation of the oceans. Ann. Rev. Fluid Mech., 36, 281-314.

Xie, S.-P., H. Annamalai, F. A. Schott and J. P. McCreary (2002), Structure and mechanisms of south Indian climate variability, J. Climate, 9, 840-858.

Zhai, X., Greatbatch, R. J. and E. Carsten (2007), Spreading of near-inertial energy in a $1 / 12^{\circ}$ model of the North Atlantic Ocean. Geophys. Res. Lett., 34, L10609, doi:10.1029/2007GL029895.

Zhai, X., Greatbatch, R. J. and E. Carsten (2009), On the loss of wind-induced near-inertial energy to turbulent mixing in the upper ocean. J. Phys. Oceanogr., 39, 3040-3045.

Zhang, C., (2005), Madden-Julian Oscillation, Rev. Geophys., 43, RG2003, doi:10.1029/2004RG000158. 